\title{
A Modeling- and Process-Oriented Study to Investigate the Projected Change of ENSO-Forced Wintertime Teleconnectivity in a Warmer World
}

\author{
MARIE DROUARD ${ }^{\mathrm{a}}$ AND CHRISTOPHE CASSOU \\ CECI UMR 5318 CERFACS/CNRS, Toulouse, France
}

(Manuscript received 4 December 2018, in final form 14 August 2019)

\begin{abstract}
Considerable uncertainties remain about the expected changes of ENSO and associated teleconnectivity as the climate is warming. Two ensembles of pacemaker experiments using the CNRM-CM5 coupled model are designed in a perfect model framework to contrast ENSO-forced teleconnectivity between the preindustrial period versus a warmer background state (obtained from a long stabilized simulation under late-twenty-firstcentury RCP8.5 constant forcing). The most notable sensitivity to the mean background state is found over the North Atlantic, where the ENSO-NAO teleconnection is considerably reinforced in a warmer world. We attribute this change to (i) a stronger and eastward-extended mean upper-level jet over the North Pacific, (ii) an eastward-shifted ENSO teleconnection over the North Pacific, and (iii) an equatorward-shifted and reinforced mean jet over the North Atlantic. These altogether act as a more efficient waveguide, leading to a better penetration of synoptic storms coming from the Pacific into the Atlantic. This downstream penetration into the North Atlantic basin forces more systematically the NAO through wave breaking. The reinforcement in the teleconnection is asymmetrical with respect to the ENSO phase and is mainly sensitive to La Niña events. Even though the Pacific jet tends to retract westward and move northward during cold events, mean changes are such that both Pacific and Atlantic jets remain connected in a warmer climate by contrast to the preindustrial period, thus ensuring preferred anticyclonic wave breaking downstream over the North Atlantic leading ultimately to NAO+ events.
\end{abstract}

\section{Introduction}

The El Niño-Southern Oscillation (ENSO) is the leading mode of climate variability in the tropical Pacific at interannual time scales. ENSO is also an important actor for global weather and climate through worldwide atmospheric teleconnections. Over the North PacificNorth American domain, the ENSO teleconnection is particularly pronounced in wintertime (Van Loon and Madden 1981; Horel and Wallace 1981; Lau and Nath 1994; Straus and Shukla 2002; Pozo-Vázquez et al. 2001) and tends to extend eastward toward the North Atlantic-European (NAE) sector, as shown by several observational and numerical studies (Van Loon and Madden 1981; Fraedrich 1990; Fraedrich and Müller 1992; Dong et al. 2000; Pozo-Vázquez et al. 2001, 2005;

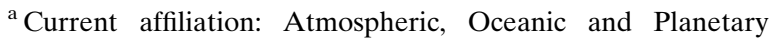
Physics, University of Oxford, Oxford, United Kingdom.
}

Corresponding author: Marie Drouard, marie.drouard@physics. ox.ac.uk
Lin et al. 2005; Brönnimann 2007; Li and Lau 2012a,b; Drouard et al. 2015; Jiménez-Esteve and Domeisen 2018, among others). Warm ENSO (El Niño) winters have been reported to be colder and drier than average over northern Europe, while precipitation tends to increase over parts of the Mediterranean. Such a meridional temperature contrast over the European continent is associated with higher sea level pressure (SLP) over Iceland and Scandinavia and lower SLP over central and western Europe, which projects onto the negative phase of the North Atlantic Oscillation (NAO-). During cold ENSO (La Niña) winters, atmospheric circulation anomalies are dominated by the $\mathrm{NAO}+$, leading to roughly opposite impacts over Europe (Pozo-Vázquez et al. 2001, 2005). Brönnimann (2007) stated that ENSO signals over the NAE domain are mostly symmetric between El Niño and La Niña, with the exception of the eastern Mediterranean domain where changes appear to be much less robust (Pozo-Vázquez et al. 2005).

Several mechanisms can explain the link between ENSO and the North Atlantic atmospheric circulation in winter. Some studies (Pozo-Vázquez et al. 2001; 
Cassou and Terray 2001) showed that the eastward extension of the Pacific-North American (PNA) teleconnection pattern affected by El Niño is responsible for NAO-like pressure anomalies over the NAE domain. Others (Ineson and Scaife 2009; Li and Lau 2013; Domeisen et al. 2015; Jiménez-Esteve and Domeisen 2018, among others) suggested that ENSO influences the NAO via stratosphere-troposphere coupling. More recently, a few papers ( $\mathrm{Li}$ and Lau 2012a,b; Drouard et al. 2015) have highlighted the importance of tropospheric synoptic Rossby wave trains in the establishment of the link between ENSO and NAO. They showed that ENSO-induced low-frequency Rossby wave trains over the North Pacific modify the propagation of the synoptic wave trains from the North Pacific to the North Atlantic basin, which impacts their breaking over the North Atlantic and thus the position of the North Atlantic jet (Drouard et al. 2015).

Based on greenhouse gases emission scenario numerical experiments analyzed in the Fifth Assessment Report of the Intergovernmental Panel on Climate Change (IPCC; Christensen et al. 2013), there is a very high degree of confidence that ENSO will remain the leading mode of interannual climate variability in the tropical Pacific in a warmer world and will continue to have a worldwide impact on weather and climate. However, associated teleconnections are expected to change in location and strength either because (i) the intensity, frequency, and pattern of ENSO SST anomalies are modified, in other words, the source of the teleconnection is altered; or (ii) the mean background atmospheric circulation is changed leading to amplification/inhibition of the above listed processes that support the existence of the teleconnection itself in the Northern Hemisphere; or (iii) a combination of both (Yeh et al. 2018).

Changes in ENSO SST properties are uncertain in future scenarios (e.g., Collins 2000; Meehl et al. 2006; Cai et al. 2015) and appear to be very much model dependent (Collins et al. 2005). However, evidence is provided that tropical convection anomalies during ENSO events are sensitive to change in the SST mean state pattern (Xie et al. 2010) and in particular to the spatial heterogeneity of the warming in the tropical Pacific, leading ultimately to different ENSO impacts through altered teleconnection (Cai et al. 2014). Over the Northern Hemisphere, several studies showed that ENSO, in a warmer world, still forces low-frequency large-scale Rossby wave trains over the North Pacific-North American domain but pointed out the eastward displacement of the overall pattern (Meehl and Teng 2007; Kug et al. 2010; Stevenson 2012). Zhou et al. (2014) went further based on ensemble runs of the CAM4 atmospheric stand-alone global circulation model (AGCM), in which they impose strictly identical El Niño SST global anomaly composite, drawn from observations, on top of an ocean climatology representing either present or future warmer climate taken from models. They showed that the shift of the ENSO-induced North Pacific-North American Rossby wave train is robust and is mostly attributable in their model to the eastward migration of the El Niñoforced tropical convective anomalies. Over the NAE region, Müller and Roeckner (2008) and Herceg Bulić et al. (2012) suggested a future increase in the ENSO teleconnection, which projects onto a NAO-like response, based on ECHAM5 coupled Atmospheric Ocean GCM and the atmospheric component of the Simplified Parameterizations Primitive Equation Dynamics (SPEEDY) intermediate complex model, respectively.

Despite numerous studies, firm conclusions are still difficult to draw regarding the modifications of ENSO teleconnection as climate is warming, due to four main reasons:

- Over the instrumental period, observations are too short to detect any significant changes because of intrinsic ENSO diversity (e.g., central vs eastern Pacific events, amplitude and seasonal phasing; Capotondi et al. 2015) and because of the presence of strong internal atmospheric variability due to extratropical stochastic noise and/or ocean-atmosphere interaction at both interannual and decadal time scales (e.g., López-Parages et al. 2015).

- Over the NAE region, uncertainties in the forced ENSO response are even bigger compared to the North Pacific sector, as assessed either from large ensemble simulations or statistical bootstrapping techniques applied on the observational records (Brands 2017; Deser et al. 2017).

- When twenty-first-century scenario experiments based on coupled GCM are contrasted to preindustrial or present-day simulations (e.g., Müller and Roeckner 2008), it is usually impossible to clearly disentangle the mechanisms leading to changes in ENSO teleconnection because they correspond to a combination of factors (modification of ENSO dynamics and SST imprint, spatial displacement and altered intensity of the related diabatic source in the tropical atmosphere, changes in extratropical stationary and synoptic waves activities, changes in background states, etc.) on top of strong internal variability (Christensen et al. 2013).

- In models, limits also exist in protocols. Atmospheric stand-alone models forced by anomalous SST patterns, aka AMIP, are traditionally used, but coupling 
with the ocean is found to be important in the midlatitudes to reinforce the atmospheric response originally forced by the tropics [e.g., Kwon et al. (2011), for the North Pacific].

In the present study, we propose to use the so-called pacemaker or partial coupling protocol in a perfect model framework to overcome the above-mentioned limitations and flaws. Our objective is to identify the dynamical processes leading to changes in ENSO teleconnection by the late twenty-first century (compared to the preindustrial period) that are solely due to changes in the mean background climate. We focus more particularly on the winter teleconnection with the NAE atmospheric circulation and, to a lesser extent, on that with the North Pacific atmospheric circulation. The paper is organized as follows: the model and methods are introduced in section 2. Results are presented in section 3 and further discussed in section 4.

\section{Data and methods}

\section{a. The CNRM-CM5 coupled model}

We use the fifth version of the CNRM-CM suite of GCM developed jointly by Météo France and the Centre Européen de Recherche et de Formation Avancée en Calcul Scientifique (CERFACS) and extensively evaluated in phase 5 of the Coupled Model Intercomparison Project (CMIP5; Taylor et al. 2012). The CNRM-CM5 atmospheric component is Action de Recherche de Petite Echelle Grande Echelle (ARPEGE)-Climat-5.2 (Déqué et al. 1994) run with a T127 triangular horizontal truncation; the diabatic fluxes and nonlinear terms are computed on a $\sim 1.4^{\circ} \times$ $1.4^{\circ}$ Gaussian grid and 31 levels in the vertical axis (including 26 levels in the troposphere). The highest level is $10 \mathrm{hPa}$. The ocean model is part of a model hierarchy based on the Nucleus for European Modelling of the Ocean (NEMO) core (Madec 2008). CNRM-CM5 uses version 3.2 , run globally on the ORCA triangular $1^{\circ}$ resolution with some refinement at the equator on the order of $1 / 3^{\circ}$. There are 42 levels in the vertical, including 18 in the first $250 \mathrm{~m}$. The sea ice model is the 5.2 version of Global Experimental Leads and Ice for Atmosphere and Ocean (GELATO; Salas Mélia 2002), which is directly embedded in NEMO and has the same grid. The Surface Externalisée (SURFEX) module, embedded in ARPEGE, is used to compute energy and water fluxes at the surface. The coupling among all the components is carried out through the OASIS3 coupler (Valcke 2013) at a daily basis. More details on model and on its overall performance can be found in Voldoire et al. (2013).

\section{b. Model protocol}

We first compute the traditional Niño-3.4 $\left(5^{\circ} \mathrm{S}-5^{\circ} \mathrm{N}\right.$, $170^{\circ}-120^{\circ} \mathrm{W}$ ) monthly SST index from the 850 -yr-long preindustrial control experiment (piControl) of CNRMCM5 produced for CMIP5. Cumulated density functions (CDFs) are built from all the possible 30-yr chunks of data in piControl (see Fig. 1a) and a period representative of strong ENSO variability has been selected for the pacemaker experiments at the core of this paper (see Fig. 1a). CNRM-CM5 is restored toward the above-selected 30-yr monthly SST anomalies over a broad eastern tropical Pacific domain (from $180^{\circ}$ to the eastern coasts of Central and South America and from $20^{\circ} \mathrm{S}$ to $20^{\circ} \mathrm{N}$; see white box in Fig. 1b), as inspired by Kosaka and Xie (2013). By contrast to the latter study using a fixed SST restoring equal to 10 days, surface restoring is done here through the introduction of a feedback term added to the nonsolar total heat flux in the surface temperature derivative equation following Haney (1971). This flux formulation affects the entire ocean mixed layer and following the recommendations of Boer et al. (2016) for CMIP6, we set the restoring strength to $-40 \mathrm{~W} \mathrm{~m}^{-2} \mathrm{~K}^{-1}$, which is equivalent to a $\sim 2$-month restoring time scale for a $50-\mathrm{m}$ ocean mixed layer depth. Note also that, as opposed to Kosaka and Xie (2013), restoring is applied here toward the model SST anomalies and not the observed ones. This perfect model framework avoids introducing artificial heat imbalance because of potential mismatch between observed restored patterns and systematic biases in coupled model variability; this is crucial to minimize spurious drifts that can eventually alter the conclusion (e.g., Sanchez-Gomez et al. 2016).

Two ensembles of 10 members of 30 -yr simulations are conducted. These differ only by the monthly climatology upon which the SST anomalies are restored: in the first ensemble, referred to as restorePIC, the SST climatology comes from the average of the first 300 years of piControl and the model is restored in the eastern tropical Pacific toward the following monthly SST:

$\mathrm{SST}_{\text {eastern tropical Pacific }}=\mathrm{SST}_{\text {piControl }}^{\prime}+\overline{\mathrm{SST}_{\text {piControl }}}$,

where primes and overbars indicate the anomaly and climatology parts, respectively. Recall that the rest of the ocean is fully coupled and the initial conditions used for the ensemble genesis come from a random selection of 10 ocean + atmosphere + land + sea ice states in piControl [so-called macroperturbation following Hawkins et al. (2016) nomenclature]. In the second ensemble, referred to as restore2085, the model 

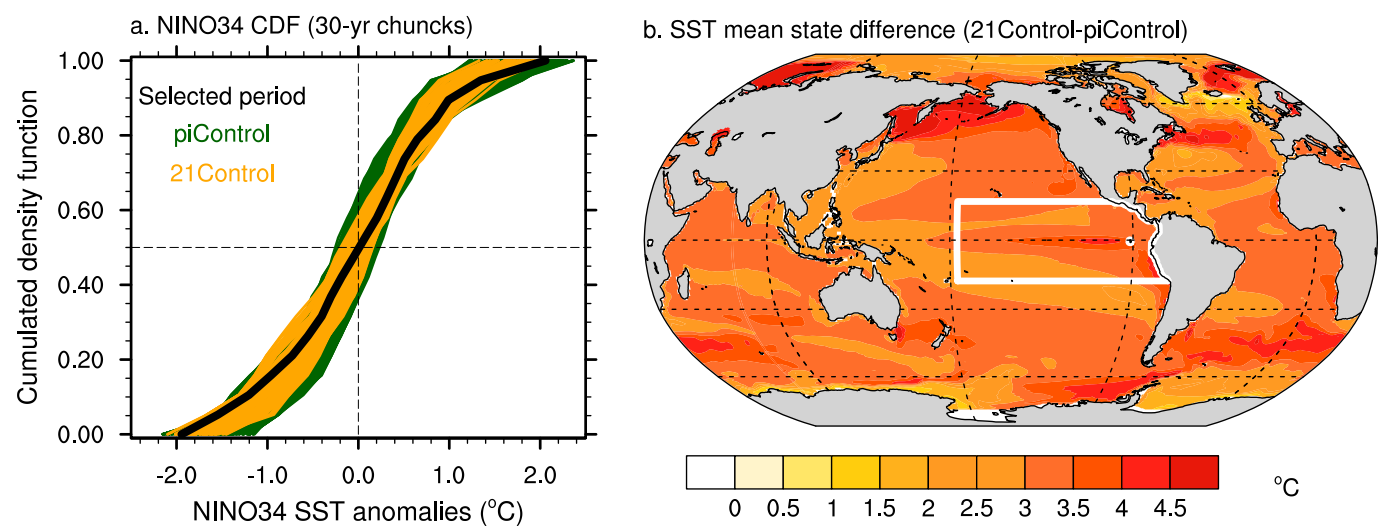

c. NINO34 SST monthly anomalies in restore ensembles

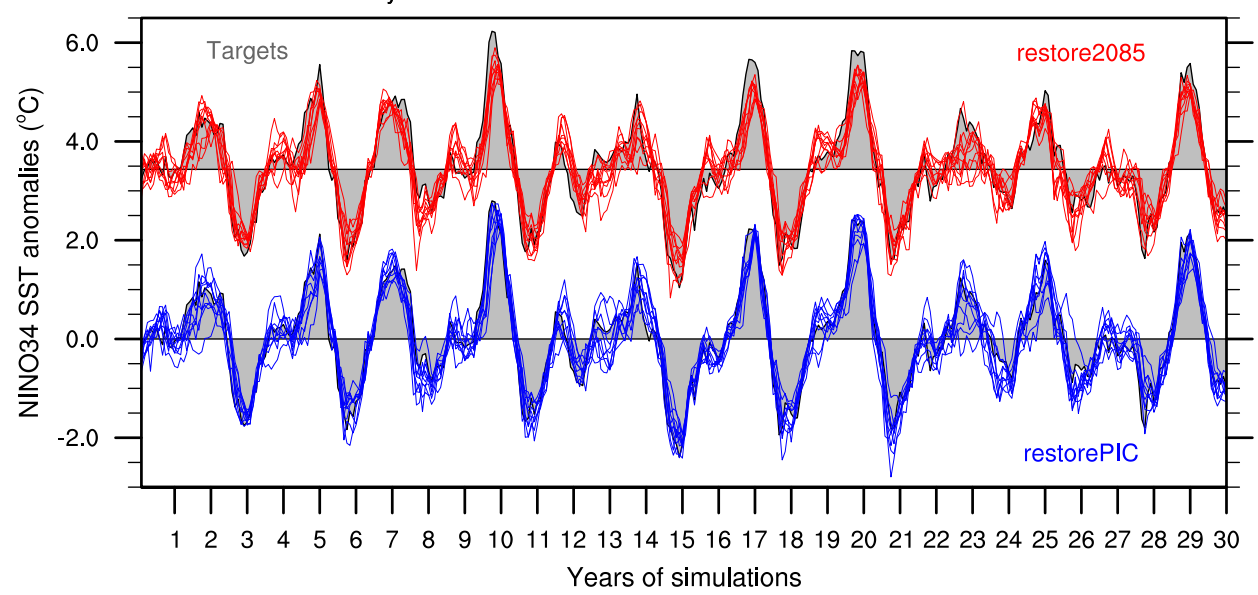

FIG. 1. (a) Cumulative density function of the Niño-3.4 SST index for all the possible 30-yr chunks available in piControl (green lines) and 21Control (orange lines) and for the selected 30-yr period (black line) used for restoring in pacemaker ensembles. (b) Mean annual SST difference between 21Control and the first 300 years of piControl. The white box represents the domain where restoring is applied in pacemaker ensembles. (c) Niño-3.4 SST anomalies for the targets (black lines and gray shading) and for each members of restorePIC (blue lines) and restore2085 (red lines).

is restored in the eastern tropical Pacific toward the following SST:

$\mathrm{SST}_{\text {eastern tropical Pacific }}=\mathrm{SST}_{\text {piControl }}^{\prime}+\overline{\mathrm{SST}_{21 \text { Control }}}$,

with the monthly SST climatology coming in that case from a 300-yr stabilized experiment of CNRM-CM5 (21Control) where external forcings are set constant to their 2085 values based on RCP8.5 scenario, as documented in Oudar et al. (2017). By construction, the restored SST anomalies over the eastern tropical Pacific are strictly identical between the two ensembles, which only differ by their mean background state shown in Fig. 1b. CNRM-CM5 warming is fairly close to the CMIP5 multimodel ensemble mean (see Christensen et al. 2013) with a maximum SST increase of $4^{\circ} \mathrm{C}$ along the Pacific cold tongue. Similarly, to restorePIC, initial conditions for the restore2085 10 -member ensemble come from a random macroselection of states in 21Control. See Table 1 for a description of the different runs.

Figure 1c illustrates the model setup and validates the protocol over Niño-3.4. Black curves represent the target SST anomalies toward which the coupled model is restored. By construction, those are identical for the two ensembles providing a mean climatological shift equal to $+3.4^{\circ} \mathrm{C}$. The spaghetti curves correspond to the individual members for the restorePIC (navy blue) and restore2085 (red) ensembles. Correlations over 30 years between target and individual members Niño-3.4 SST indices range from 0.94 to 0.96 for restorePIC members and from 0.90 to 0.94 for restore 2085; ensemble means are correlated at 0.98 an 0.96 , respectively. Figure 1c provides evidence that 
TABLE 1. Summary of the four runs performed.

\begin{tabular}{|c|c|c|c|c|}
\hline Run & $\begin{array}{c}\text { Duration } \\
\text { (years) }\end{array}$ & Members & Forcing & Climatology used for the restoring \\
\hline piControl & 850 & 1 & Fixed at year 1850 values & - \\
\hline 21Control & 300 & 1 & $\begin{array}{l}\text { Fixed at year } 2085 \text { values of the RCP } 8.5 \\
\text { scenario }\end{array}$ & - \\
\hline restorePIC & 30 & 10 & Fixed at year 1850 values & Climatology of piControl \\
\hline restore2085 & 30 & 10 & $\begin{array}{l}\text { Fixed at year } 2085 \text { values of the RCP } 8.5 \\
\text { scenario }\end{array}$ & Climatology of 21Control \\
\hline
\end{tabular}

the temporal evolution of ENSO is very well constrained in both ensembles despite a rather weak restoring term. This shows that the modeling protocol used here is well adapted to isolate the role of the background state in the modification of ENSO teleconnections as climate is warming, when the statistical ENSO properties of the anomalous SST do not significantly change. We verify that the Niño-3.4 SST index $\mathrm{CDF}$ of the 30 -yr period selected in piControl is compatible with future climate variability materialized in Fig. 1a by the envelop of CDFs built similarly from all the possible $30-\mathrm{yr}$ chunks of data in 21Control.

\section{c. Model data}

Our analysis is based on seasonal and daily means from these four experiments (piControl, 21Control, restorePIC, and restore2085). We only consider winter months from December to February (DJF) and we have verified that our results based on CNRM-CM5 are not sensitive to the definition of the season (not shown), as opposed to Moron and Gouirand (2003) and Ayarzaguiena et al. (2019), who suggest different teleconnectivity between early and late winter. Several fields were used: the geopotential height at $500 \mathrm{hPa}$ (Z500), zonal and meridional winds at $200 \mathrm{hPa}, 2-\mathrm{m}$ temperature, and precipitation. Dynamical fields were decomposed into high-and low-frequency parts, using a Lanczos filter with a cutoff period of 7 days, to separate the synoptic-scale signal from that of the low-frequency part (Duchon 1979).

\section{d. Analysis tools}

Traditional regression statistics will be used in this paper together with composite analyses and weather regimes to investigate the asymmetry of the teleconnection changes with respect to the two ENSO phases. To analyze the synoptic Rossby wave propagation in the Northern Hemisphere during ENSO events, we use time-lag regressions of unfiltered wintertime daily meridional wind at $200 \mathrm{hPa}$ and extended Eliassen-Palm E vectors following $\mathrm{Li}$ and Lau (2012a,b) and Drouard et al. (2015).

\section{1) WEATHER REGIMES}

Weather regimes can be interpreted as quasistationary atmospheric circulations (e.g., Reinhold and Pierrehumbert 1982) during which the character of the synoptic storms is unusually persistent (Vautard 1990; Straus et al. 2007, among others). They are spatially well defined (typically the width of the oceanic basin) and limited in number and have a typical 6-10 day nominal persistence; they ideally correspond to statistical-dynamical equilibria in phase space (Molteni et al. 2006). Statistically speaking, weather regimes are classes of atmospheric circulation patterns gathered together from a criterion of similarity. Those classes are defined by their mean conditions, or centroids, by their variance and by their frequency of occurrence. They are traditionally obtained from clustering techniques. Following Michelangeli et al. (1995), we here use the $k$-means algorithm that iteratively finds the optimal partition that minimizes the ratio of the variance within clusters to the variance between clusters centroids; the criterion of similarity retained for clustering is the Euclidian distance. Reference weather regimes from CNRM-CM5 are first determined from piControl daily winter maps of SLP (from 1 December to 28 February over 850 years, i.e., 102935 days) over a geographical domain limited to the NAE $\left(20^{\circ}-80^{\circ} \mathrm{N}, 90^{\circ} \mathrm{W}-30^{\circ} \mathrm{E}\right)$. A cosine weight as a function of latitude is applied to the data a priori. The weather regimes occurrences for restorePIC and restore 2085 ensembles are computed by projecting the wintertime daily outputs of each $30-\mathrm{yr}$ member onto the reference weather regimes centroids obtained from piControl. The changes of ENSO teleconnectivity in a warmer climate are assessed below by contrasting the modification of the occurrence of the NAE regimes with respect to the restored Niño-3.4 SST anomalies, which are common in the two ensembles by construction (Fig. 1c).

\section{2) Extended Eliassen-PAlm Vectors}

The $\mathbf{E}$ vectors are computed using the formula of Trenberth (1986): 


$$
\mathbf{E}=\frac{1}{2}\left(v^{\mathrm{HF} 2}-u^{\mathrm{HF} 2}\right) \mathbf{i}-u^{\mathrm{HF}} v^{\mathrm{HF}} \mathbf{j},
$$

where $u$ and $v$ are the zonal and meridional winds, respectively. HF stands for the high-frequency part. The $\mathbf{E}$ vectors point approximately in the direction of wave energy propagation relative to the time-mean flow while their divergence and curl show the eddyinduced acceleration of the zonal and meridional winds, respectively. Here, we use $\mathbf{E}$ vectors to infer the modification of the tilt of the synoptic eddies and the orientation of their propagation with respect to the background mean state (Rivière et al. 2003; Drouard et al. 2015). When $\mathbf{E}$ vectors point equatorward eddies are elongated in the southwest-northeast direction and energy propagates equatorward (see Fig. 1 from Drouard et al. 2015). On the contrary, E vectors pointing poleward indicate northwest-southeastelongated eddies and poleward energy propagation. Last, eastward- and westward-oriented $\mathbf{E}$ vectors indicate meridional and zonal directions of elongation, respectively.

\section{Results}

\section{a. Sensitivity of ENSO teleconnection to mean background state}

Regression maps of DJF Z500 anomalies on Niño-3.4 SST index are shown in Fig. 2 for the 10 individual members of restorePIC. The ensemble mean and associated significance are also provided as an estimation of the ENSO-forced signal. A negative Z500 anomaly is found over the North Pacific to the east of the date line. It is part of the low-frequency and large-scale PNA wave train originating in the eastern tropical Pacific and extending eastward over the North American continent and North Atlantic basin. This pattern associated with ENSO has been extensively described in literature both from observations and model results (Wallace and Gutzler 1981; Van Loon and Madden 1981; Li and Lau 2012a,b; Deser et al. 2017, among others). The deepening of the Aleutian low is robust across the 10 ensemble members, but significant spread is found in intensity, extension and precise location of its fingerprint (cf. for instance member 1 with member 8 or 10). In the NAE domain, some runs show a meridional pressure dipole reminiscent of the negative phase of the NAO (see members 1,2, and 4) in agreement with previous studies in which the ENSO-NAE dynamical relationship is described mostly from observations (see introduction). Other runs show opposite patterns especially over the eastern part of the North Atlantic basin (see for instance members 5 and 8). The discrepancy is such that the
ENSO-forced response, which is best estimated by the ensemble mean, is barely significant over the North Atlantic domain except from Florida to the Azores. Thus, solely the traditional PNA pattern emerges from the noise (Fig. 2). By construction, the ensemble spread is entirely attributable to internal variability since all the members share the same ENSO-forcing SST anomalies through restoring in the eastern tropical Pacific. Our findings with CNRM-CM5 are very much in line with those described in Deser et al. (2017) based on CESM large ensembles. As stated in this study, these results have strong implications in terms of model evaluation but also in the interpretation of the decadal modulation in ENSO teleconnection recorded over the historical/ instrumental period over the North Atlantic. Considering the very pronounced level of atmospheric noise in the midlatitudes in winter, our study confirms that it seems to be virtually impossible to rule out the fact that the observed changes may not be a by-product of sampling issue, in line with Brands (2017).

The sensitivity of the DJF ENSO teleconnection to the change in the mean background state is now evaluated in Fig. 3 that is the equivalent of Fig. 2 but for the restore2085 ensemble. The forced ENSO signal estimated by the ensemble mean strongly differs between the two climates. The overall PNA pattern is shifted eastward by about $30^{\circ}$ of longitude and the teleconnection over the North Atlantic Ocean is considerably reinforced. A clear and very significant NAO- signal now emerges from the regression analysis in restore 2085 compared to the restorePIC ensemble mean. The spread between members is greatly reduced, especially over the Azores where a negative center is present in all the runs, albeit dispersed in intensity. The positive center over the North Atlantic subpolar gyre is less systematic but still much more robust than in restorePIC, leading in fine to clearer NAO - in a warmer world. Note though that ENSO teleconnection remains almost inexistent over Europe in terms of atmospheric circulation. In the North Pacific, a strong positive geopotential-height anomaly develops to the west of the date line in restore2085. In restore2085, it is particularly robust, as it is present in all members, while it is minor, barely significant, and primarily confined over Japan in restorePIC. This ENSO-forced circulation is as pronounced as the eastward displacement of the Aleutian low that is now confined along the coast of the North American continent.

The eastward shift of the PNA pattern and the emergence of the anomalous high to the west of the North Pacific basin are particularly visible in Fig. 4, which provides additional hints for its tropical origin. Despite very close ENSO SST anomalies in both 

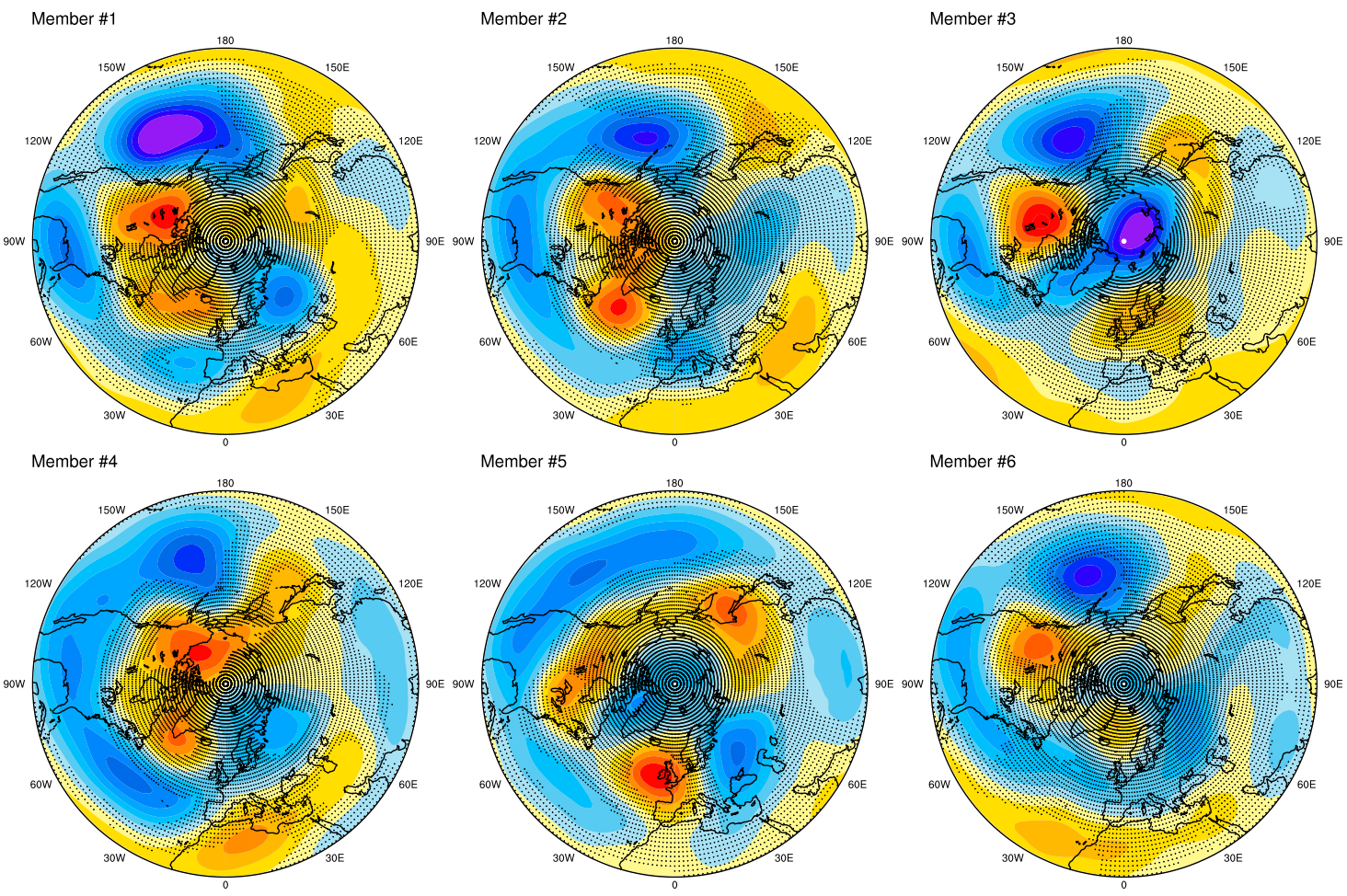

Member \#5

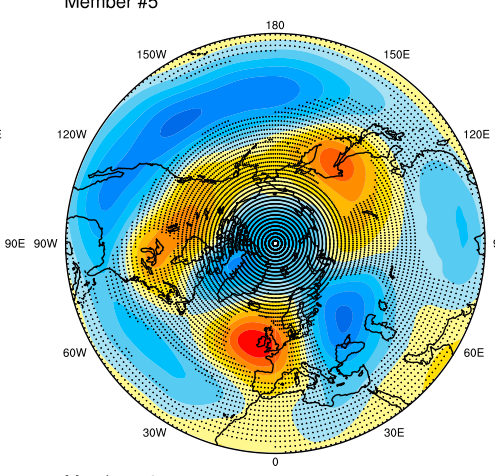

Member \#6

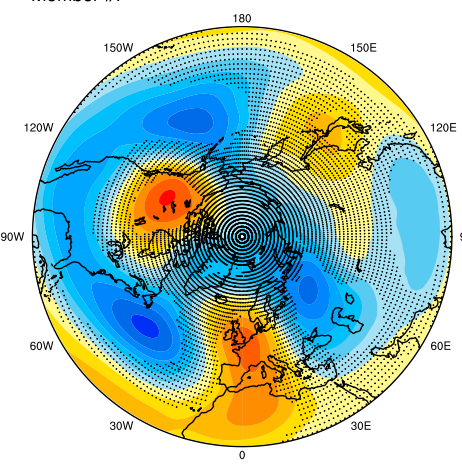

Member \#8
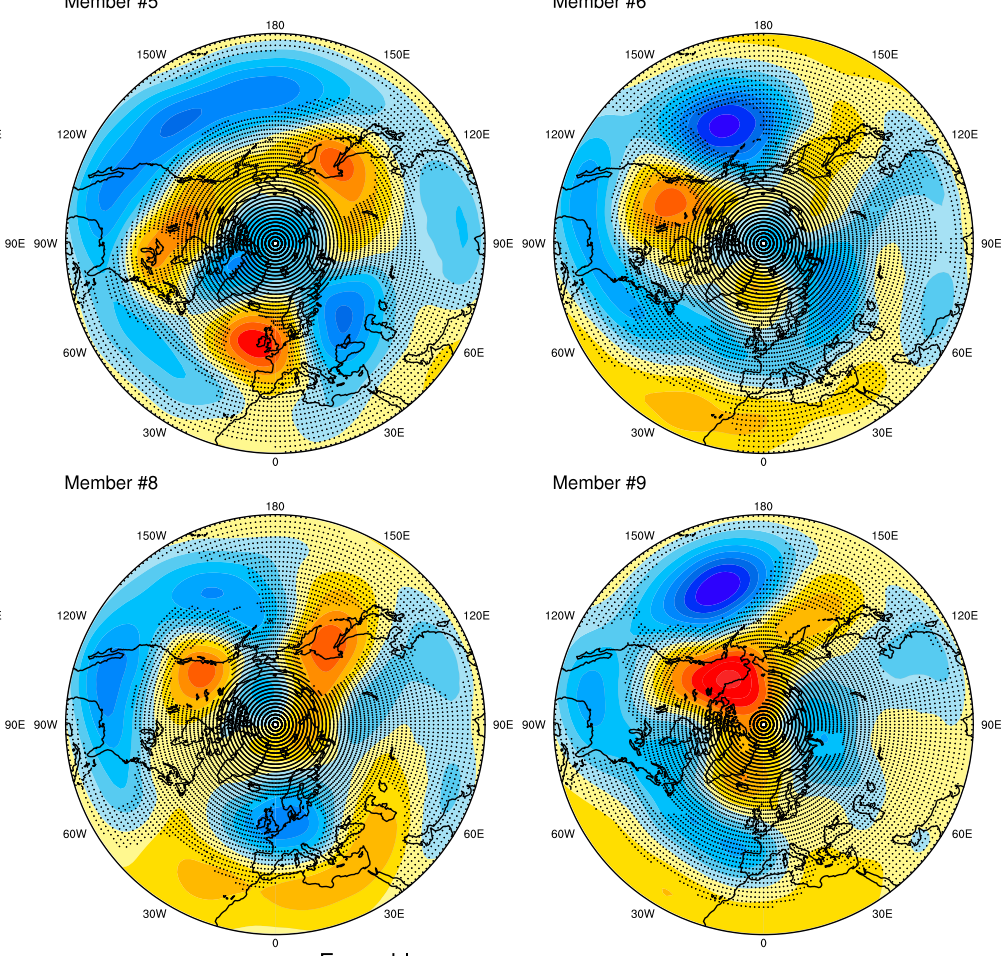

Member \#9

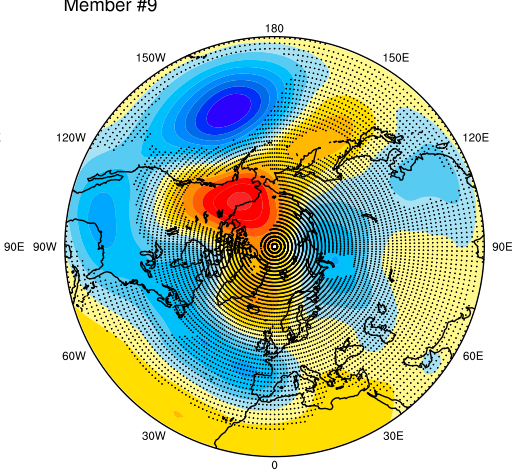

Member \#10

Ensemble mean

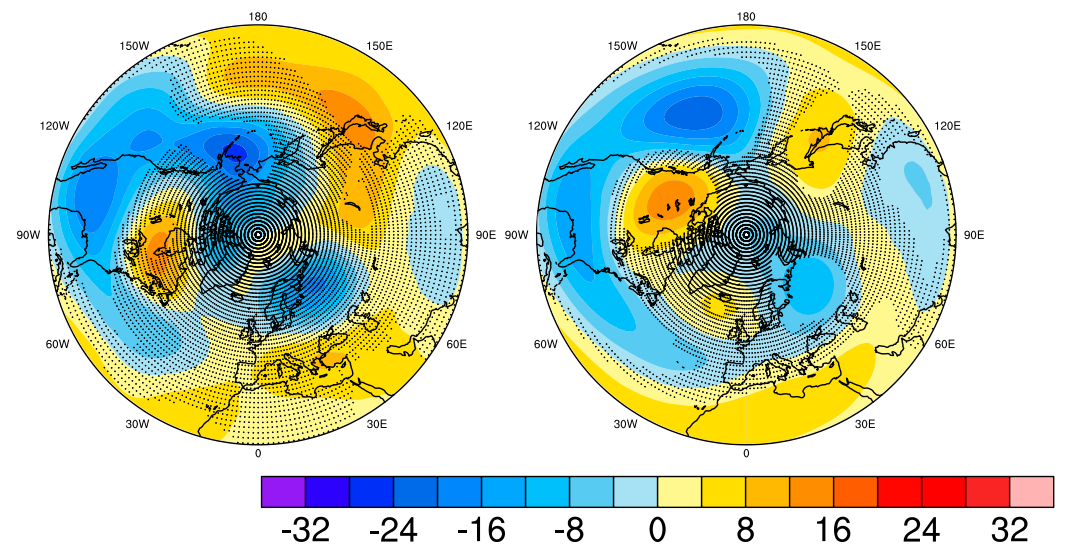

Meters

FIG. 2. Regression of DJF Z500 on the Niño-3.4 SST index for the 10 members of restorePIC and for the ensemble mean. The contour interval is $4 \mathrm{~m}$. Nonstippled areas represent significant regression coefficients based on bootstrapping statistical test at the $95 \%$ confidence level in absolute value. 

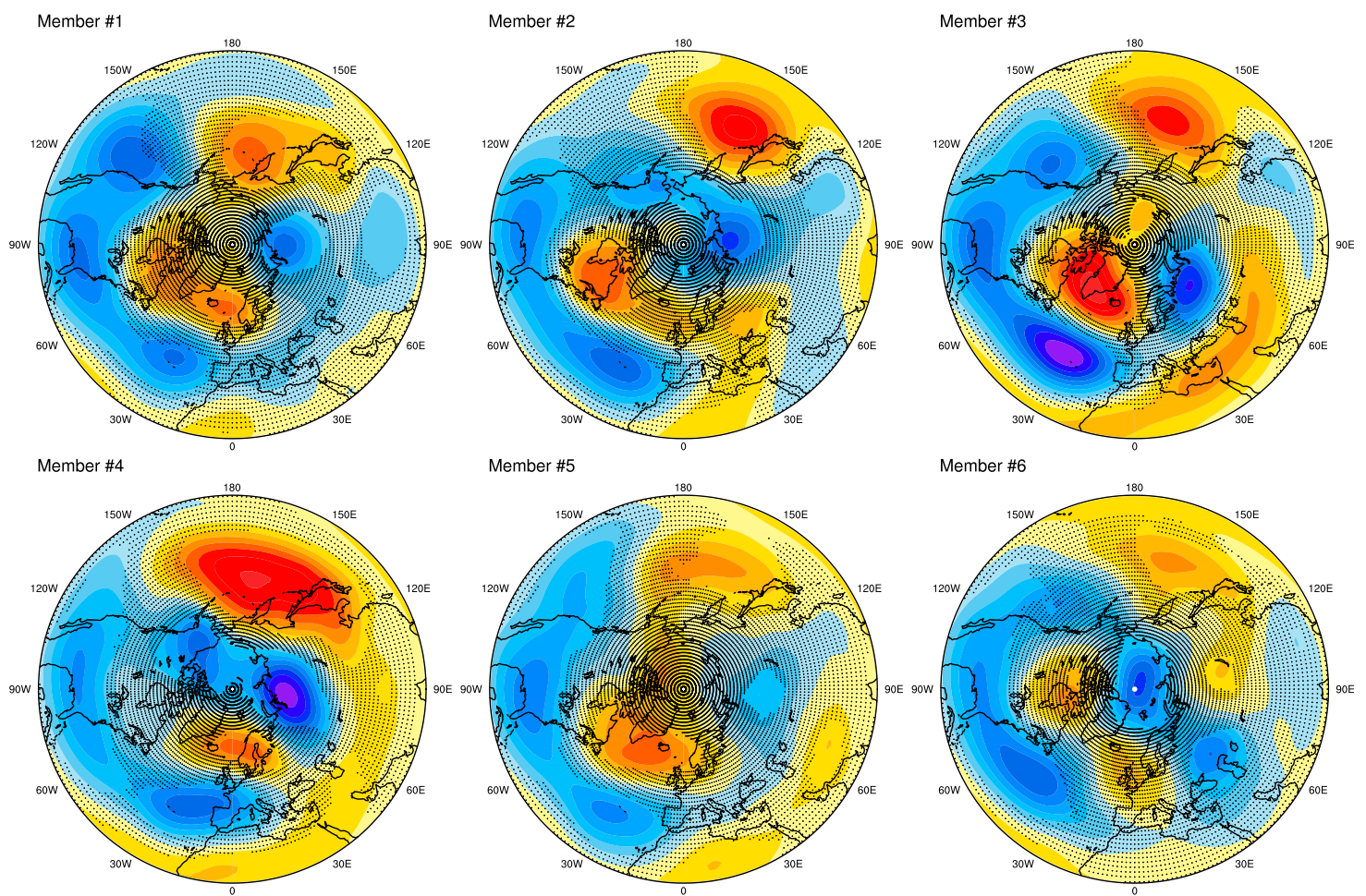

Member \#5

Member \#6
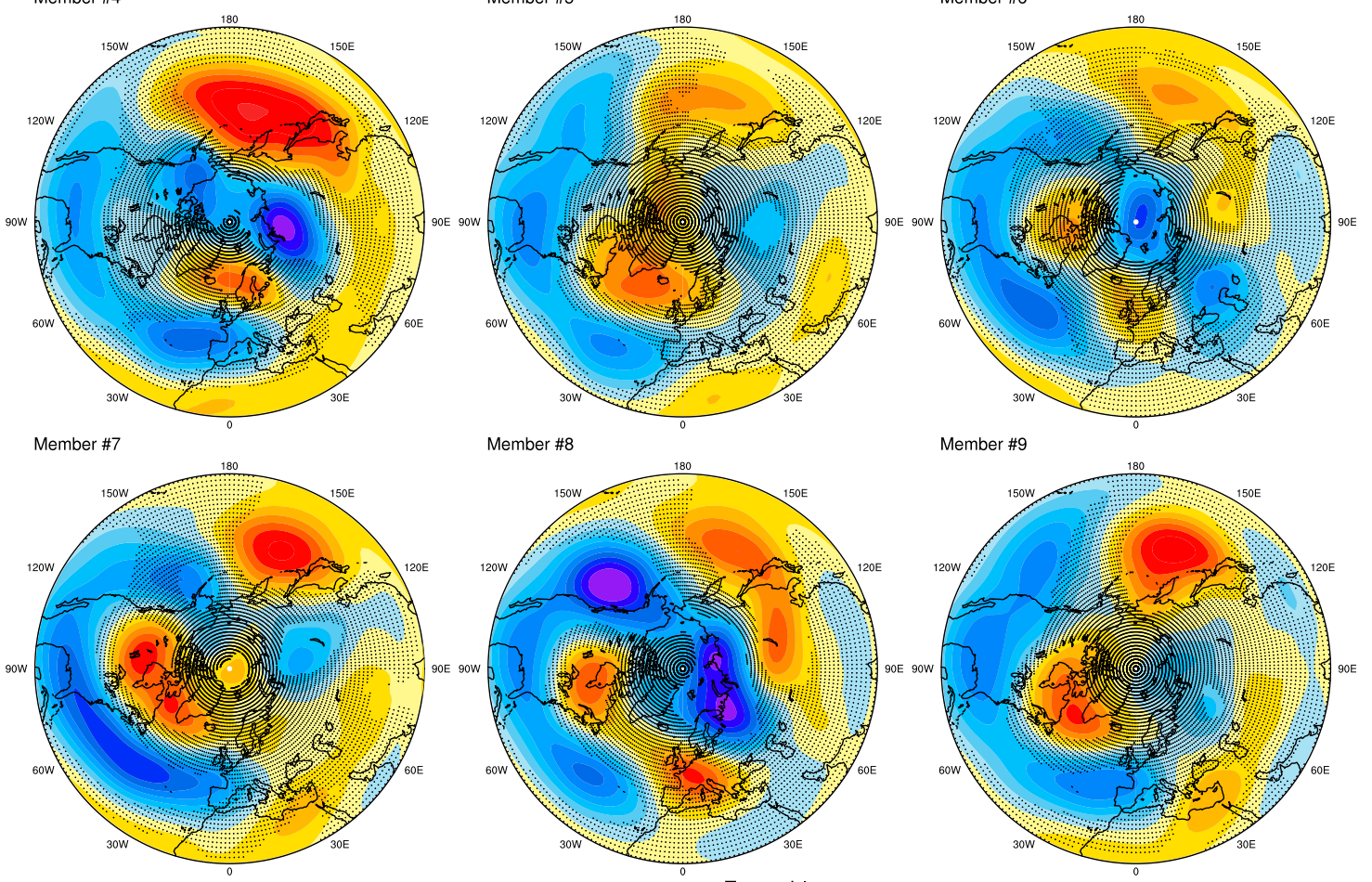

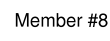

notemen
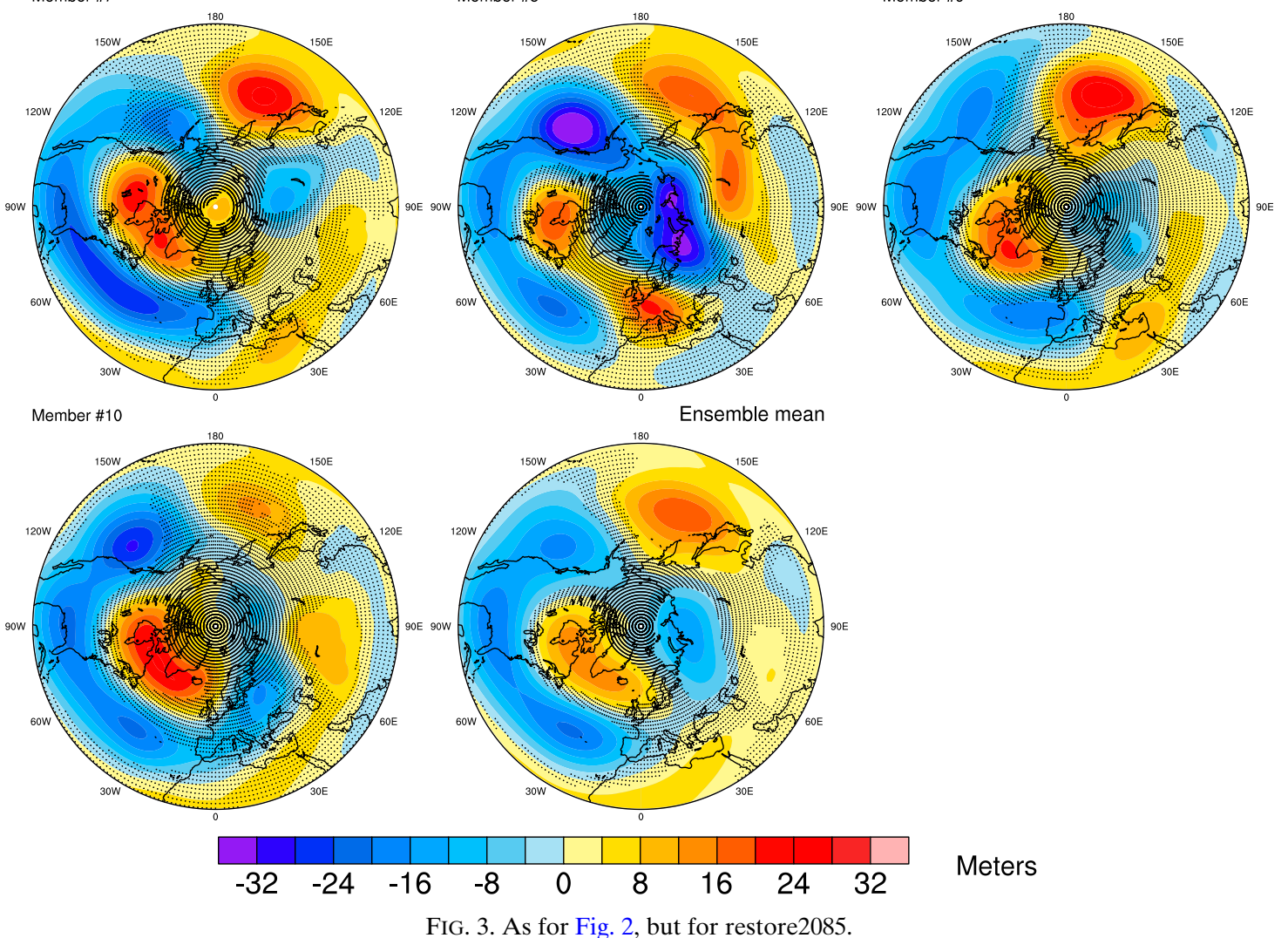

Meters

FIG. 3. As for Fig. 2, but for restore2085. 

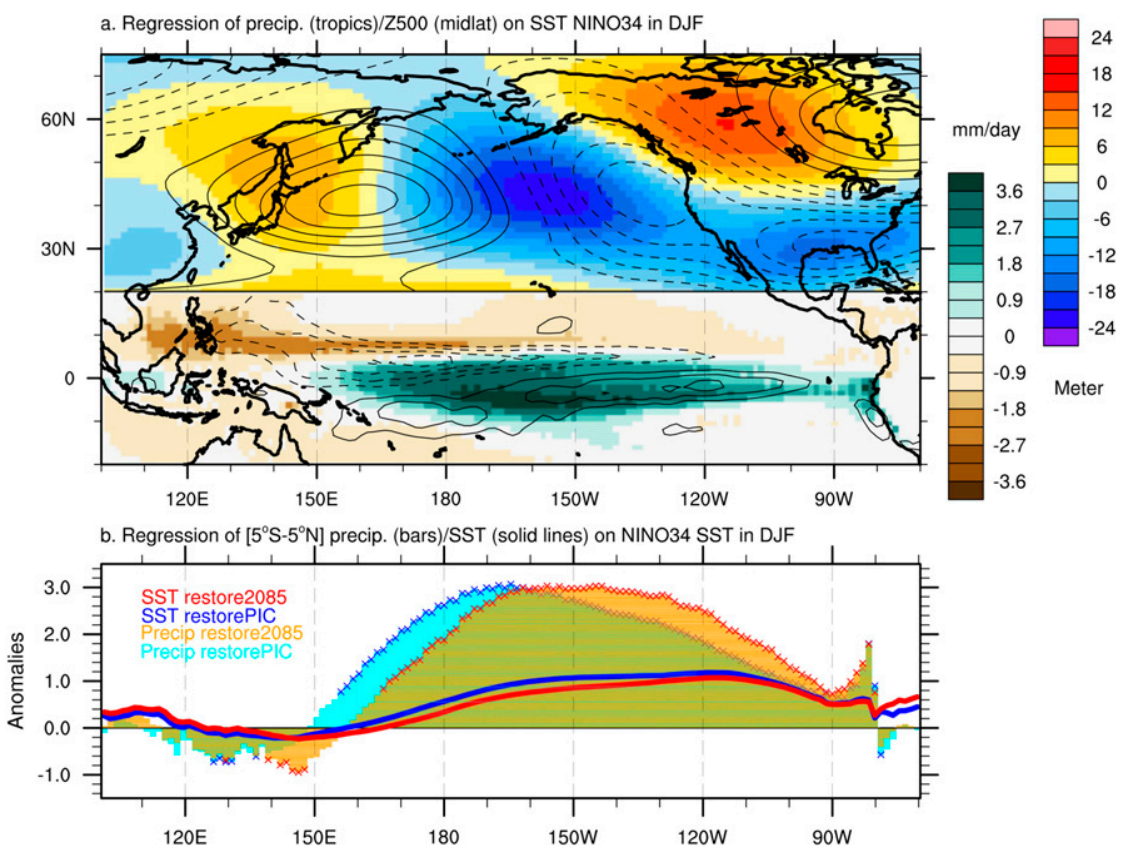

FIG. 4. (a) Ensemble mean of the 10-member regressions on the DJF Niño-3.4 SST index of (top) midlatitude Z500 and (bottom) tropical precipitation for restoreCPI in shading. Intervals are $3 \mathrm{~m}$ and $0.45 \mathrm{~mm} \mathrm{day}^{-1}$, respectively. Contours in the top panel are Z500 for restore2085. Contours in the bottom panel are the difference of regression between restore2085 and restorePIC for precipitation. (b) Ensemble means of 10-member regressions on the DJF Niño-3.4 SST for precipitation averaged between $5^{\circ} \mathrm{S}$ and $5^{\circ} \mathrm{N}$ for restorePIC (cyan bars) and restore2085 (orange bars). The thick lines are for SST for restorePIC (blue) and restore2085 (red). Crosses represent significant regression coefficients based on bootstrapping statistical test at the $99 \%$ confidence level in absolute value.

restorePIC and restore 2085 over the tropical band by construction, the maximum precipitation response is clearly moved to the east by about $30^{\circ}$ along the equator (Fig. 4b). This eastward shift is linear and is characterized during La Niña winters by an eastward extension of the drier area (not shown). Figure $4 \mathrm{a}$ shows that the associated displacement of diabatic heating, through enhanced convection, anchors the midlatitude atmospheric circulation to the east, following classical forced Rossby wave source theory (Hoskins and Karoly 1981). Such a displacement is concurrent with reinforced dryness to the northwest of the tropical Pacific (Figs. 4a,b) that is indicative of further reduction of the Walker cell in a warmer climate during ENSO. Depleted diabatic heating over a larger domain to the north is associated with enhanced rainfall south of the equator, featuring a modification of the local Hadley cell in the western tropical Pacific. This all together provides an additional source of Rossby waves for extratropical circulation, but opposite in sign with respect to the central/eastern basin, and accordingly responsible for the emergence of the midlatitude ENSO-forced anomalous high to the west of the date line (Fig. 4a) in line with Zheng et al. (2013).

As described in Power et al. (2013) and Cai et al. (2014) among others, the eastward shift of the convection zone during El Niño is facilitated by the diminution of mean SST gradients in the tropical Pacific under greenhouse gas-induced warming conditions since the cold tongue warms greater than the surrounding area. This is true for CNRM-CM5 (Fig. 1b) and explains why greater precipitation along the equator together with more efficient Walker cell reduction is generated in restore 2085 versus restorePIC although exact same SST anomalies are imposed in the model through restoring. The eastward shift of the Aleutian low found in restore2085 in response to ENSO is consistent with previous studies based on twenty-first-century climate projections (see IPCC Fifth Assessment Report, Christensen et al. 2013), despite discrepancies between models (e.g., Meehl and Teng 2007; Kug et al. 2010; Stevenson 2012). As stated in the introduction, Zhou et al. (2014) provide compelling evidence for its tropical origin using AGCM forced by ENSO composite global SST anomalies diagnosed from 
observation and superimposed on different mean background states as well as AMIP-type CMIP5 experiments including CNRM-CM5.

Over the North Atlantic, the emergence of a significant NAO- teleconnection pattern in restore2085 in response to ENSO is in good agreement with the results from Müller and Roeckner (2008) and Herceg Bulić et al. (2012). By construction, as opposed to projections traditionally used in literature, our dedicated protocol allows us to conclude that such an appearance of the teleconnection pattern over the NAE domain is solely related to the changes in the mean background state in a warmer climate and not to the modification of the ENSO-induced SST anomalies. In the next section, we present the underlying physical mechanisms, which link ENSO to the North Atlantic dynamics in a warmer world.

\section{b. Asymmetry between El Niño and La Niña events and role of synoptic eddies}

To investigate the processes leading to robust ENSO signal over the NAE domain in a warmer climate, we need to go beyond linear analyses and investigate the asymmetry of the newly teleconnection with respect to the ENSO phase by analyzing El Niño and La Niña events separately. We also need to consider highfrequency mechanisms, hereafter evaluated from model daily outputs.

\section{1) WeAther REgimes}

Decomposition of the North Atlantic wintertime atmospheric circulation in weather regimes is first used to get further insight into the teleconnection changes. As mentioned in the data and methods section, we use daily SLP maps from the 850-yr piControl experiment and perform a regime decomposition based on the $k$-means algorithm. The most robust partition following Michelangeli et al. (1995) criteria to evaluate the significance of the decomposition, is obtained for $k=5$ in CNRM-CM5 as opposed to $k=4$ in the observations [see Cassou (2008) for more details]. The positive and negative NAO regimes, also referred to as zonal and Greenland anticyclone circulations, respectively, are relatively well represented in the model (Figs. 5a,b), although too spatially symmetrical compared to observations. The blocking (BL) and Atlantic ridge (AR) regimes are also relatively well captured (Figs. 5c,d). The fifth weather regime is characterized by negative SLP anomalies over the British Islands (Fig. 5e); it will be termed accordingly BI-. This regime projects upon the negative phase of the east Atlantic pattern and its presence is associated with the climatological biases in CNRM-CM5, which tends to simulate too zonal and eastward-displaced storm track/upper-level jet over the North Atlantic, leading to spurious enhanced variance off western Europe (see Voldoire et al. 2013, their Fig. 3).

The right column of Fig. 5 shows the number of days of occurrence for each weather regime for both restorePIC and restore2085 ensembles as a function of Niño-3.4 SST index stratified into deciles. Horizontal dashed lines stand for mean occurrence and reveal an averaged increase in $\mathrm{NAO}+$ weather regimes in restore2085 ( +8 days) compensated by diminished $\mathrm{NAO}-(-4$ days $)$ and $\mathrm{BI}-(-7$ days $)$ circulations, whereas mean statistics are not significantly altered for $\mathrm{AR}$ and BL. More importantly, on top of mean background occurrence changes, the sensitivity of NAO regimes to the phase of ENSO considerably differs in a warmer climate as shown by the change of the slope in the regression lines. While a slight (but not significant) tendency for more frequent $\mathrm{NAO}+$ regimes can be found in restorePIC during La Niña events, it is strongly reinforced in restore2085 (Fig. 5a); the excess of NAO + is clearly compensated by a deficit of NAOepisodes (Fig. 5b). On the contrary, the mean background change does not significantly modify the occurrence of both NAO regimes during moderate-tostrong El Niño events (upper quartile of the Niño-3.4 SST distribution). The other regimes remain insensitive to ENSO phases whatever the background climate, except for BI-, but to a very low extent, since its excitation is slightly favored during La Niña versus El Niño events in restore 2085 .

Our findings suggest that the enhanced ENSO teleconnection in a warmer climate, evidenced in the linear regression maps (Figs. 2 and 3), could be interpreted as the fingerprint of the reinforced sensitivity of the NAE dynamics to La Niña events preferably. Consistently with this nonlinearity, the asymmetrical change in teleconnection with respect to the phase of ENSO would partly contribute to the rectification onto the mean NAE dynamics in a warmer climate. Alternatively, changes in mean background circulation could modify some aspects of the NAE dynamics and in particular processes involved in NAO variability, which appears to be the most responsive to ENSO in a warmer world as assessed in CNRM-CM5. Even if it is difficult to clearly disentangle all the factors and mechanisms at play, an attempt is provided in the following based on the analysis of synoptic wave propagation between the Pacific and Atlantic basins.

\section{2) EDDY-MEAN FLOW INTERACTION}

Figure 6 shows the daily evolution of synoptic wave trains that are generated along the North Pacific storm 

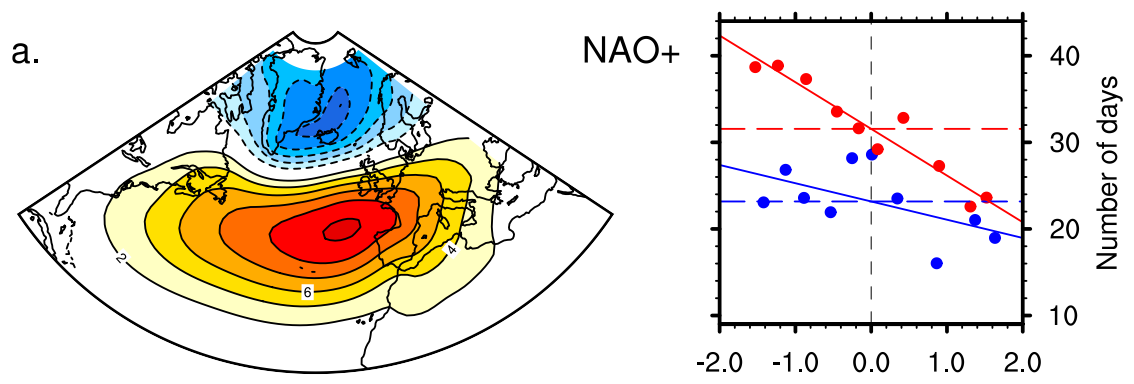

b.

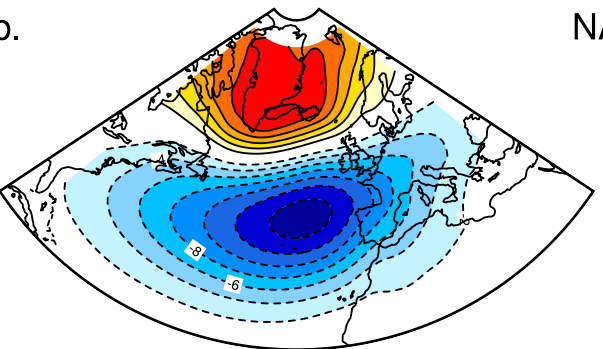

c.

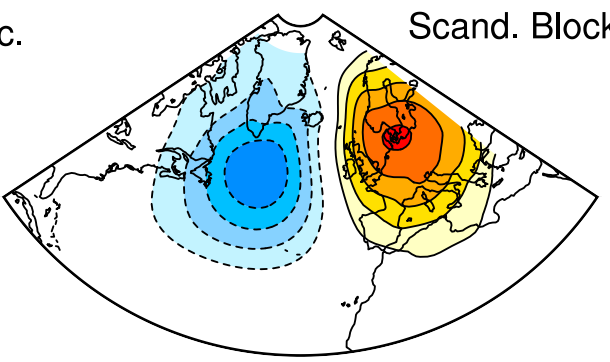

d.
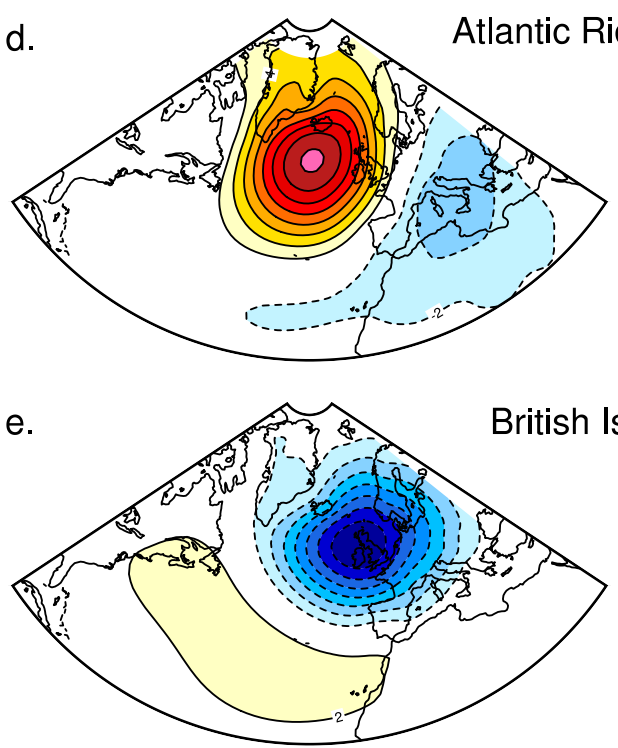

NAO-

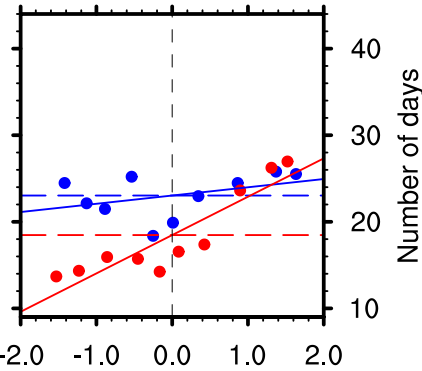

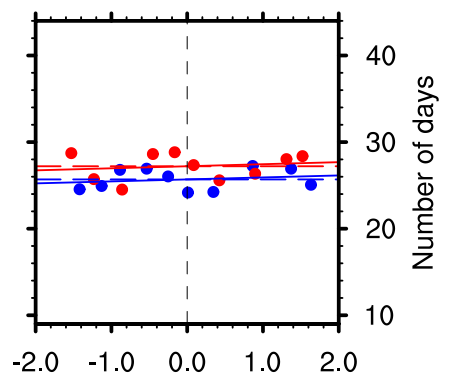
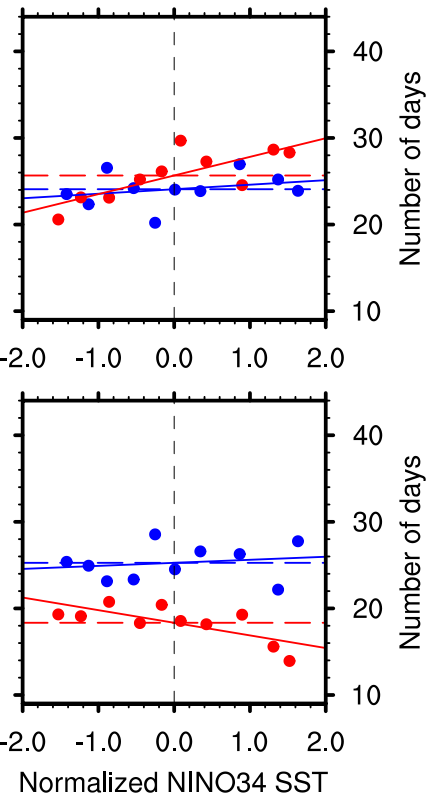

FIG. 5. (left) Centroids of the five SLP weather regimes in piControl. Contour interval is $2 \mathrm{hPa}$. (right) Mean occurrence (days) for each weather regime as a function of decile of the Niño-3.4 SST index for restorePIC (blue curves and dots) and restore2085 (red curve and dots). Computations are done from 10 members $\times 92$ days per winter $\times 29$ winters $=27600$ days taken individually. The dashed blue (red) lines represent the averaged occurrence of the restorePIC (restore2085) ensemble independently of ENSO. The solid lines represent the linear regression between occurrences and Niño-3.4 SST anomalies. 
restorePIC
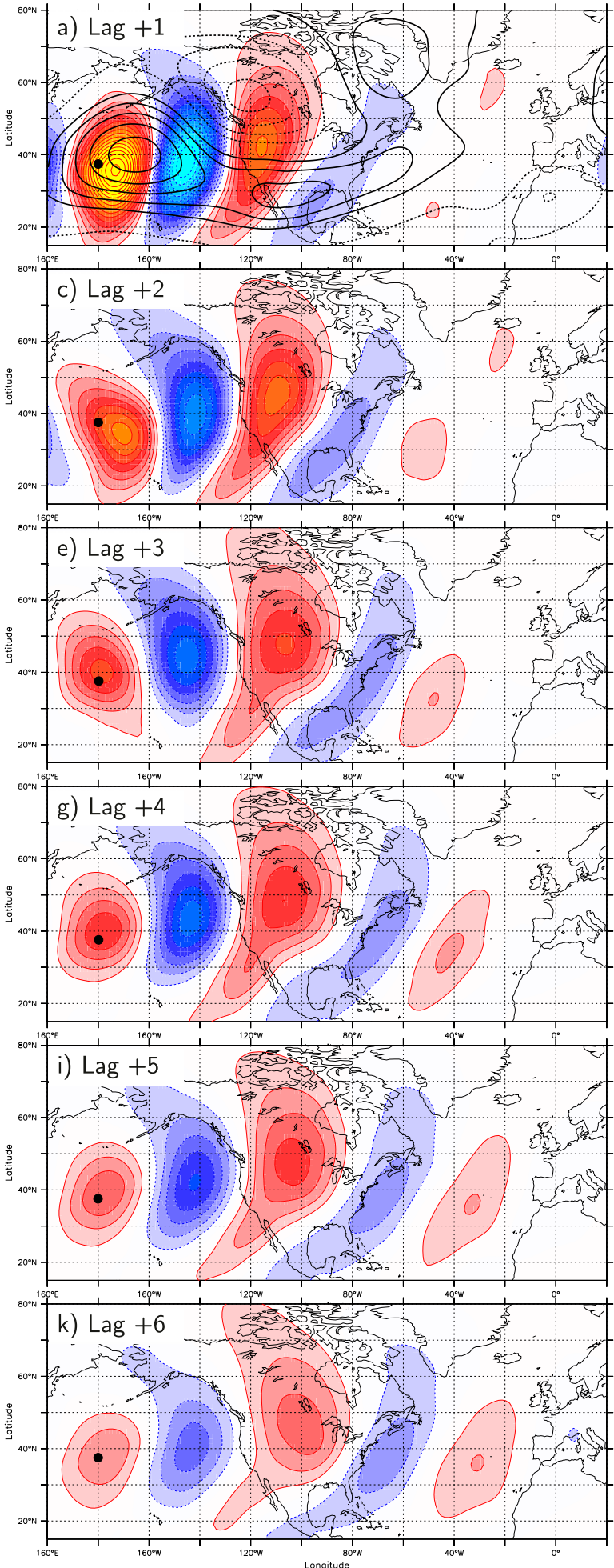

restore2085
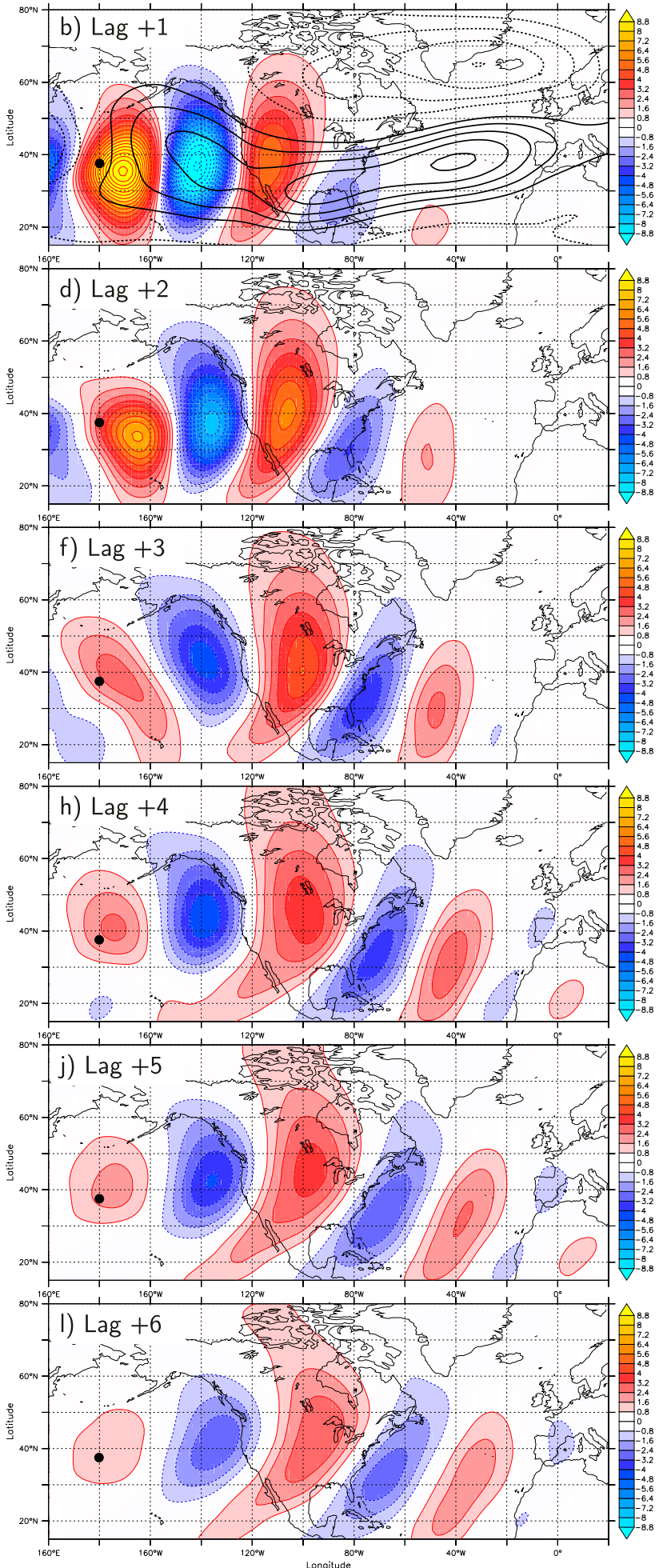

FIG. 6. Lagged autoregressions (days) of the 200-hPa unfiltered meridional wind anomaly (shading; interval is $0.8 \mathrm{~m} \mathrm{~s}^{-1}$ ) on one reference point at $37.5^{\circ} \mathrm{N}, 180^{\circ}$ (black dot) for the (left) restorePIC and (right) restore 2085 ensembles. Computations are done for December-February winters days of La Niña events only (Niño-3.4 SST anomalies lower than -1 std dev). Mean composite of Z500 anomalies during La Niña are provided in (a) and (b) (contours; interval is $5 \mathrm{~m}$ ). 
track and propagates downstream toward the North Atlantic domain during La Niña winters. Corresponding composites of DJF Z500 anomalies are superimposed in the top panels and restorePIC and restore2085 ensembles are contrasted. Consistently with the results shown in Fig. 5, there is no signal in Z500 over the NAE sector during La Niña in restorePIC (Fig. 6a) as opposed to restore2085 where a clear $\mathrm{NAO}+$-like dipole emerges from the composite (Fig. 6b). Over the North Pacific, in agreement with the regression maps previously shown in Figs. 2 and 3, the PNA pattern is shifted eastward in a warmer climate. The La Niña-driven anomalous high off the American continent is also less pronounced and there is a clear junction between the Canadian negative pole shifted over the Hudson area in restore2085 and the NAE dynamics.

The temporal propagation of the synoptic waves originating in the Pacific is assessed through one-point lagged regression of 200-hPa daily unfiltered meridional wind anomalies as inspired by Li and Lau (2012b) and Drouard et al. (2015), among others. The base point of the regression $\left(37.5^{\circ} \mathrm{N}, 180^{\circ}\right)$ is located upstream of the large-scale PNA-like Rossby wave train forced by ENSO. At lag +1 day (Figs. 6a,b) and at lag 0 (not shown), the synoptic wave packets are similar in restorePIC and restore 2085 ensembles. Then, the wave trains propagate poleward on the upstream side of the North Pacific ridge but clearly equatorward on its downstream side. Synoptic eddies are then elongated in a southwest-northeast direction and keep this tilt when they enter into the North Atlantic domain. As shown in previous studies, the direction of elongation of the synoptic waves is an important parameter for the sign of subsequent Rossby wave breakings in the North Atlantic domain, which is ultimately related to the phase of the NAO (Benedict et al. 2004; Franzke et al. 2004; Rivière and Orlanski 2007; Cassou 2008; Strong and Magnusdottir 2008; Vallis and Gerber 2008; Woollings et al. 2008). In the literature, it is demonstrated that synoptic wave packets with southwest-northeast tilt tend to break anticyclonically and trigger the NAO+ when breakings occur on the southern side of the jet. The opposite is found with synoptic wave trains showing no preferred elongation leading preferably to NAO-.

Interestingly, whatever the mean background state, synoptic eddies entering the North Atlantic domain show a clear southwest-northeast tilt, which tends to favor the $\mathrm{NAO}+$ phase (see for instance lag +4 days). However, considerable differences are found in terms of intensity, eastward penetration and latitudinal position of the wave packet. The latter (i) is much more energetic in a warmer climate (see from lag +3 to $\operatorname{lag}+6$ days), which is indicative of a stronger connection between
North Pacific and North Atlantic storm tracks as discussed later; (ii) penetrates farther east; and (iii) is southward shifted by about $5^{\circ}-8^{\circ}$ in latitude over the entire midlatitude Atlantic. Based on the above-listed studies related to eddy-mean flow processes, these factors clearly support for better efficiency/increased probability to get $\mathrm{NAO}+$ circulation over the NAE domain during La Niña winters in a warmer world. Differences between restorePIC and restore2085 are much less noticeable during El Niño years (not shown). Wave trains are then north-south elongated in both ensembles favoring in fine NAO-circulation. Similar to La Niña, they are reinforced in a warmer climate but are located at the same latitude in both restorePIC and restore2085 ensembles. Thus, these results demonstrate that during $\mathrm{El}$ Niño winters in restorePIC the Pacific and Atlantic dynamics are already well connected, and this connection is simply strengthened in restore 2085.

Composites of $\mathbf{E}$ vectors and momentum fluxes $\left(u^{\mathrm{HF}} v^{\mathrm{HF}}\right)$ intensity provided in Fig. 7 tend to confirm the above-mentioned interpretations. During La Niña in the preindustrial background climate, significant enhanced equatorward-pointing $\mathbf{E}$ vectors with respect to climatology are confined over the United States at the entrance of the mean Atlantic jet (Fig. 7a), whereas they extend up to Europe in restore2085 (see difference in Fig. 7b). This supports the hypotheses that synoptic Rossby waves may break over the whole basin in a warmer climate during La Niña and their sign (enhanced equatorward vector) is representative for anticyclonic dissipation leading to enhanced occurrence of NAO+ phase. This is also corroborated by the momentum fluxes intensity that is stronger over southern Europe or northern Africa in restore2085 versus restorePIC ensemble. During El Niño events, propagation of synoptic wave trains is more zonal and enhanced poleward $\mathbf{E}$ vectors are found along the North Atlantic storm track in the preindustrial climate (Fig. 7c). In a warmer world, no significant changes occur except that the latter pattern extends considerably more eastward toward Europe and is slightly reinforced. This is also shown by the increase in momentum flux intensity over southern Europe (see difference in Fig. 7d). Note that for El Niño, significant more equatorward $\mathbf{E}$ vectors are found off the California coast in coherence with the shifted El Niño-driven PNA pattern and overall reduced teleconnectivity over the North Pacific (lower deepening of the Aleutian low in restore2085; see Fig. 2 vs Fig. 3 ).

To conclude, these three figures clearly show that a more systematic excitation of the NAO+ phase is expected during La Niña events in restore2085 compared 

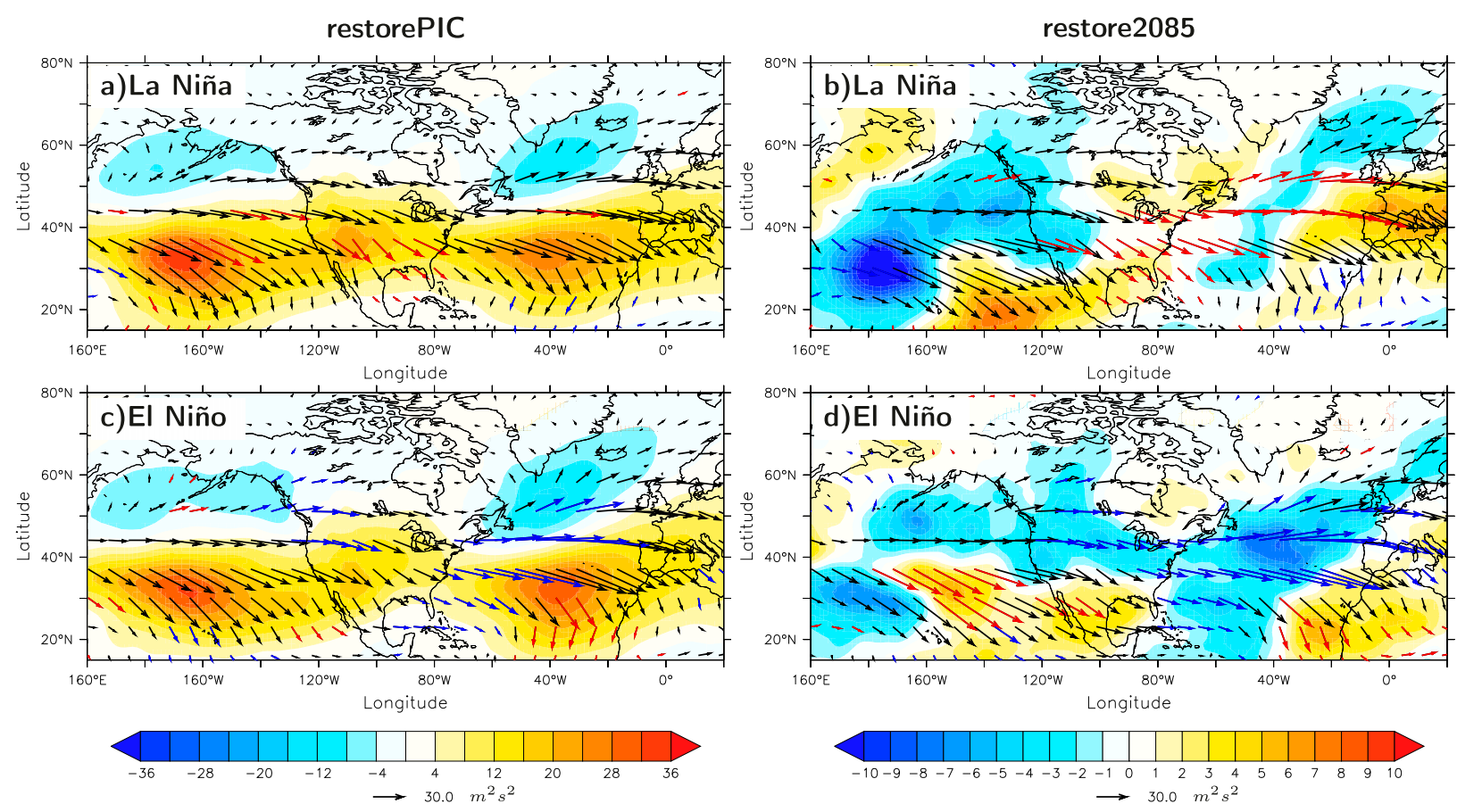

FIG. 7. (left) DJF composites of ensemble-mean $u^{\mathrm{HF}} v^{\mathrm{HF}}$ momentum fluxes (shading; interval is $4 \mathrm{~m}^{2} \mathrm{~s}^{-2}$ ) and $\mathbf{E}$ vectors (arrows; see scale below the color bar) for restorePIC for (a) La Niña (Niño-3.4 SST $<-1$ std dev) and (c) El Niño (Niño-3.4 SST $>+1$ std dev) events. (right) Difference in the DJF composites of ensemble-mean $u^{\mathrm{HF}} v^{\mathrm{HF}}$ momentum fluxes (shading; interval is $1 \mathrm{~m}^{2} \mathrm{~s}^{-2}$ ) between restore 2085 and restorePIC for (b) La Niña (Niño-3.4 SST $<-1$ std dev) and (d) El Niño (Niño-3.4 SST index $>+1$ std dev) events. Arrows show the DJF composites of ensemble-mean $\mathbf{E}$ vectors (see scale below the color bar). Red (navy blue) arrows indicate that the $\mathbf{E}$ vectors are significantly more equatorward (poleward) oriented than their climatological mean based on bootstrapping statistical test at the $95 \%$ confidence level.

to restorePIC. Figure 7 also shows that changes during El Niño events are less strong than during La Niña events, as the connection between the North Pacific and NAE dynamics already exists in restorePIC during El Niño events. Therefore, the reinforcement of the teleconnection is due to a much stronger sensitivity to La Niña phase in restore2085 compared to restorePIC. In the following, we investigate a possible reason for this stronger influence of La Niña events on the NAE circulation in restore2085.

\section{3) WAVEguide}

In a warmer world, the mean subtropical Pacific jet and Atlantic jet tend to be more continuous in winter in CNRM-CM5 (see differences in Fig. 8a). In the Pacific, strong acceleration of the jet occurs at the jet exit with a considerable increase (greater than $10 \mathrm{~m} \mathrm{~s}^{-1}$ ) between the date line and $130^{\circ} \mathrm{W}$ leading to a more zonal and eastward-extended North Pacific jet. Over the Atlantic, reinforcement is found at the entrance of the jet and on its southern side between $80^{\circ}$ and $40^{\circ} \mathrm{W}$ also causing zonality/extension over the whole basin at midlatitudes. This all together contributes to boosting the circumpolar waveguide properties of the jet (Branstator 2002;
Chen 2002; Manola et al. 2013) and would facilitate the propagation of synoptic wave trains between the $\mathrm{Pa}$ cific and Atlantic in a warmer climate. This is consistent with the enhanced propagation of the synoptic wave packets between the two basins, which was clearly visible in Fig. 6 for La Niña but also true for El Niño (not shown). Note also that the eastward extension of the eddy-mean flow interaction toward southern Europe (see Figs. 6 and 7) appears clearly attributable to the changes in the mean background/jet circulation over the North Atlantic (Fig. 8a).

ENSO composites of the upper-level 200-hPa zonal wind, averaged between $25^{\circ}$ and $45^{\circ} \mathrm{N}$ where the North Pacific winter jet is the strongest, show even more clearly this enhanced continuity and connection between the two basins in restore2085 (Fig. 8b). The separation between the two-basin jets is the greatest during La Niña in the preindustrial climate, as the North Pacific jet is confined to the western part of the basin. The gap between the two jets inhibits the propagation of synoptic wave packets from the Pacific (Fig. 6) and downstream related eddy-mean flow interactions over the Atlantic (Fig. 7a). By contrast during El Niño winters, the extension of the jet to the eastern Pacific is stronger by 

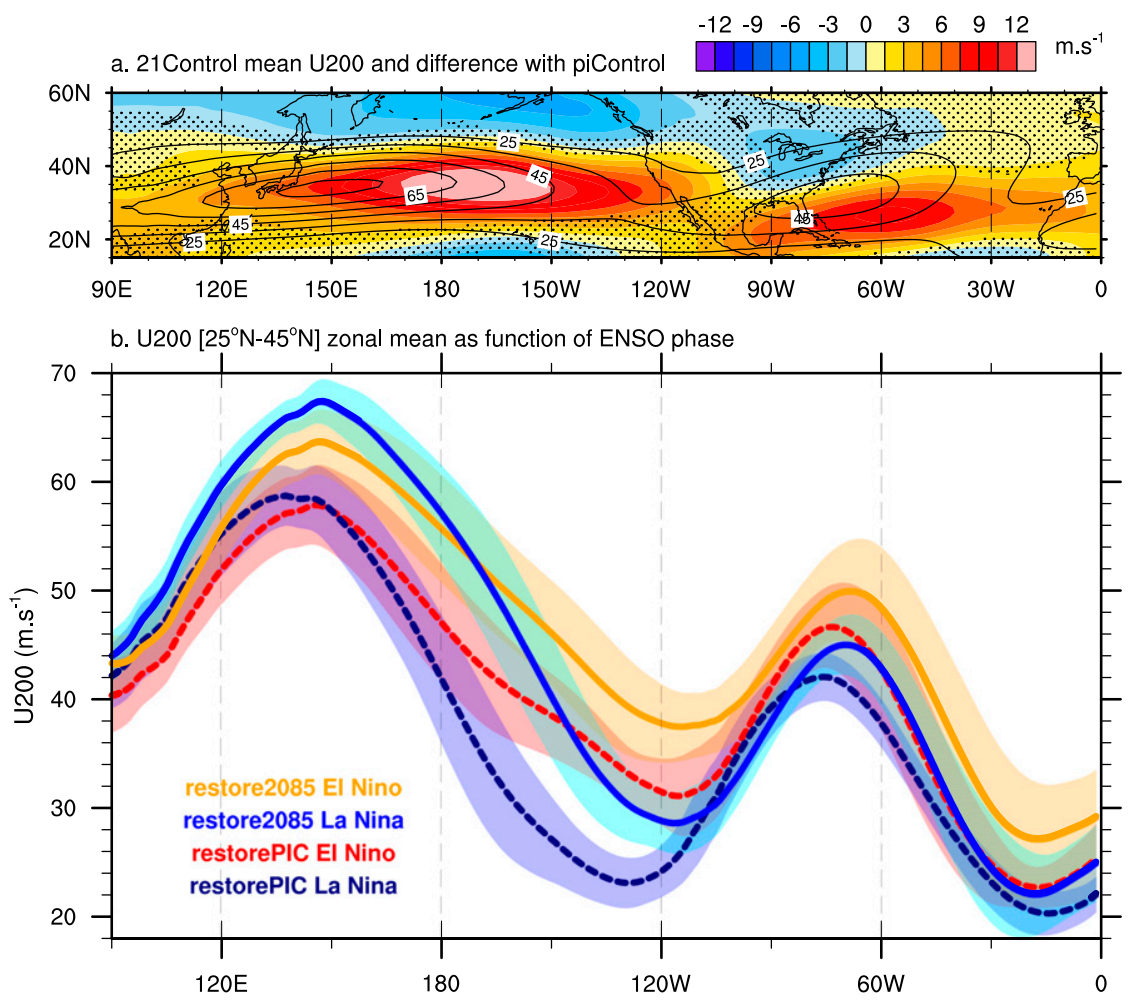

FIG. 8. (a) Mean DJF 200-hPa zonal wind in 21Control (contours; interval is $10 \mathrm{~m} \mathrm{~s}^{-1}$ starting from $25 \mathrm{~m} \mathrm{~s}^{-1}$ ) and difference with piControl (shading; interval is $1.5 \mathrm{~m} \mathrm{~s}^{-1}$ ). Nonstippled areas represent a significant difference between the two climatologies based on a two-sample $t$ test at the $99 \%$ confidence level. (b) Longitudinal profile of the DJF 200-hPa zonal wind ensemble mean averaged between $25^{\circ}$ and $45^{\circ} \mathrm{N}$ along the mean storm track during El Niño events in restorePIC (thick red dashed line) and restore2085 (thick orange solid line) and during La Niña events in restorePIC (thick dark blue dashed line) and restore2085 (thick navy blue solid line). The selection for ENSO composites, that is, El Niño vs La Niña, is based on +1 and -1 std dev of Niño-3.4 SST index, respectively. Light shaded areas show the min-max spread values among the ensemble members.

about $8 \mathrm{~m} \mathrm{~s}^{-1}$ compared to La Niña ones. This ensures greater continuity and waveguide efficiency for traveling synoptic storms into the Atlantic and thus makes feedbacks possible between Pacific-generated eddies and North Atlantic mean flow (consistently with Fig. 7c). Moreover, because of background circulation changes (enhanced subtropical jets, Fig. 8a), preindustrial El Niño dynamics is very close to La Niña one in a warmer climate in terms of jet connection between the two basins (cf. dashed red and solid blue lines, respectively, between $140^{\circ}$ and $60^{\circ} \mathrm{W}$ in Fig. $8 \mathrm{~b}$ ). So, thresholds for waveguide processes to play an active role would be more easily reachable in restore 2085 during La Niña winters compared to restorePIC. This is in good agreement with the conclusions diagnosed from Figs. 6 and 7. Moreover, most of jet mean increase occurs southward in a warmer world over the North Atlantic (Fig. 8a), which further reinforces the predisposition for southwest-northeast-elongated synoptic eddies coming from the Pacific to enter the North Atlantic domain and to break anticyclonically, leading ultimately to NAO+. During El Niño winters in restore2085, the circumpolar property of the jet is also intensified (Fig. 8b). Further research and dedicated experiments using intermediate complexity dynamical models to mimic CNRM-CM5 [e.g., quasigeostrophic models like in Marshall and Molteni (1993)] would be needed to quantify and firmly conclude about the threshold effects in the jet intensity and related eddymean flow interactions that we have hypothesized here in the course of the paper.

\section{c. Changes in ENSO impact over North America and Europe}

In terms of ENSO-driven impact, the eastward displacement of the anomalous centers of action in a warmer world lead to drastic modifications of the tropical-extratropical connectivity over the North 

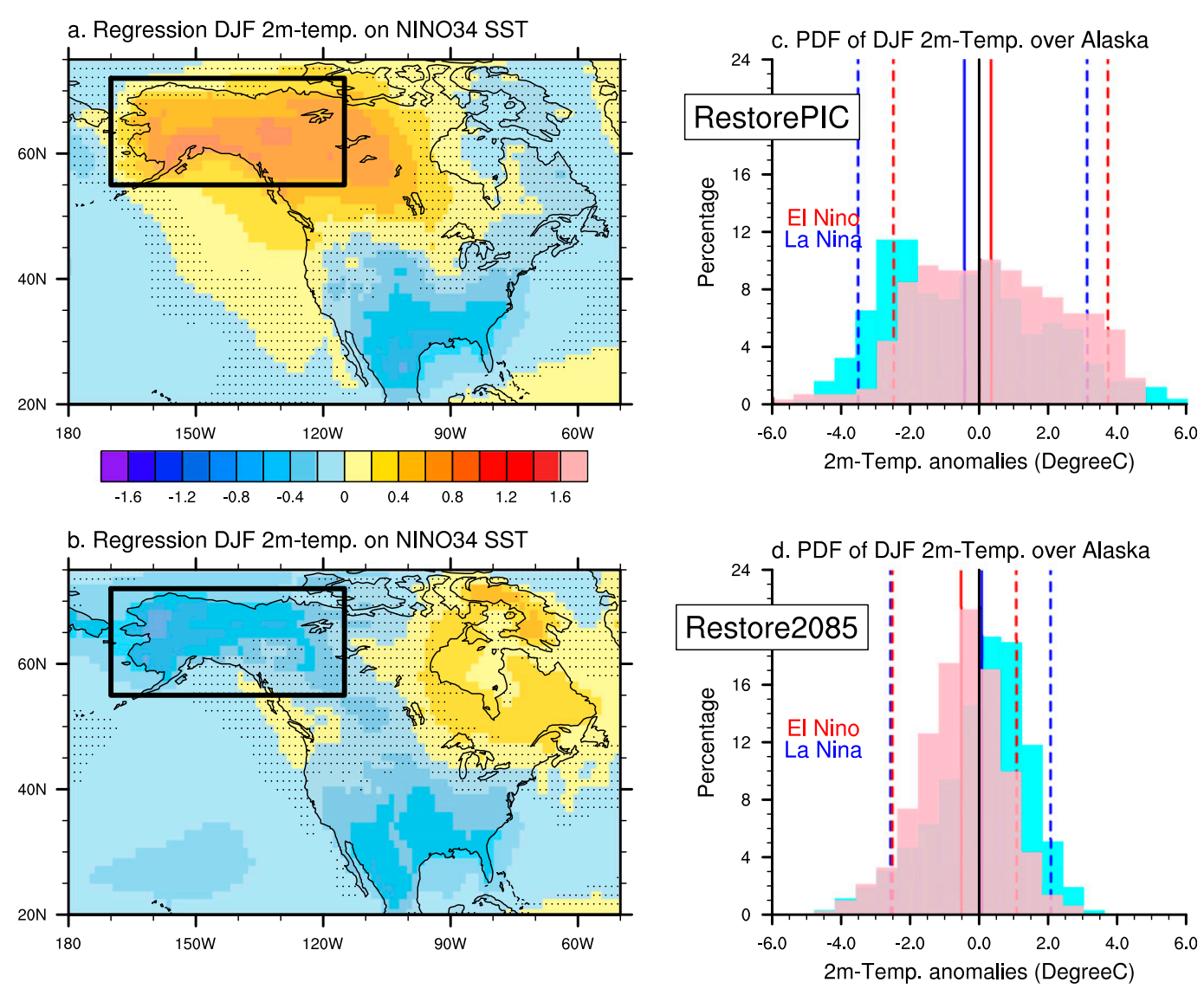

FIG. 9. (left) Ensemble means of the regression of the DJF 2m-temperature on the Niño-3.4 SST index for (a) restorePIC and (b) restore2085. Contour interval is $0.2^{\circ} \mathrm{C}$. Nonstippled areas shows where the regression coefficients are significant based on bootstrapping statistical test at the $95 \%$ confidence level. (right) PDFs of the DJF 2m-temperature averaged over Alaska and Yukon (see black box) determined from (c) restorePIC and (d) restore2085 members for El Niño (light pink) and La Niña (cyan) winters. The selection for ENSO composites, that is, El Niño vs La Niña, is based on +1 and -1 std dev of the Niño-3.4 SST index, respectively. Dashed red and blue vertical lines indicate the 5th- and 95th-percentile values of each distribution; solid lines indicate the mean values.

American continent, especially at high latitudes. The most noticeable feature is the opposite relationship found between surface temperature and ENSO over Alaska and Yukon (Figs. 9a,b). Actually, changes go beyond means and alter the entire distribution of temperature over that region. In the preindustrial climate (Fig. 9c), the ENSO phase is very much discriminant for winter cold extremes occurrence, which are mostly favored (inhibited) during La Niña (El Niño). Warmer conditions are overly dominant during El Niño as shown in Deser et al. (2018) for instance. In restore2085 (Fig. 9d), distributions undergo a drastic diminution of variance and skewness, which is associated with the massive reduction of winter snow cover and related soil-atmosphere feedback in a warmer world (e.g., Fischer et al. 2011). The ENSO phase is not discriminant any more for cold extremes and warmer conditions are now more recurrent (less frequent) during La Niña (El Niño) conversely to restorePIC. By contrast, ENSO-driven surface temperature anomalies over the United States and Mexico is fairly robust and not significantly modified by the background climate.

Figure 10, which is the counterpart of Fig. 9 but for winter precipitation over the northeast Atlantic-Europe region, clearly highlights the mean southward displacement of the tail end of the storm track in link to ENSO. It is barely visible and significant in restorePIC (Fig. 10a) but appears considerably accentuated and larger-scale in restore2085 leading to a clear dipole in western Europe precipitation (Fig. 10b). Again, regression analysis masks considerable modifications in distributions. Off southern Europe in the preindustrial climate (Fig. 10c), a slight shift toward excess rainfall 
a. Regression DJF precip on NINO34 SST

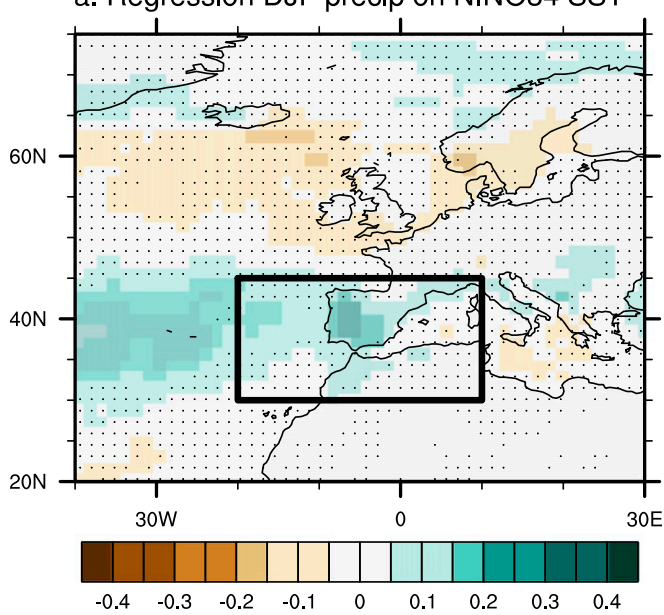

b. Regression DJF precip on NINO34 SST

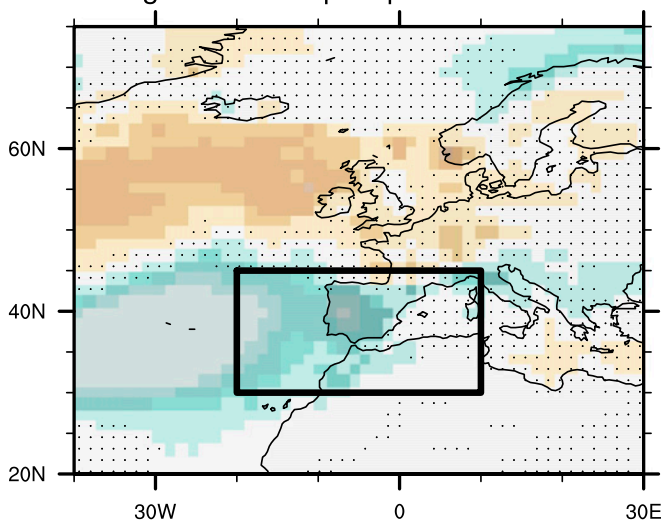

c. PDF of DJF precip.

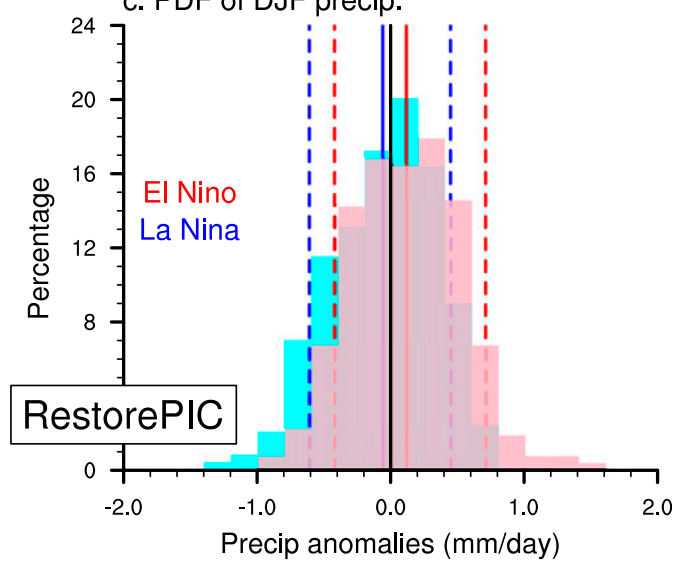

d. PDF of DJF precip.

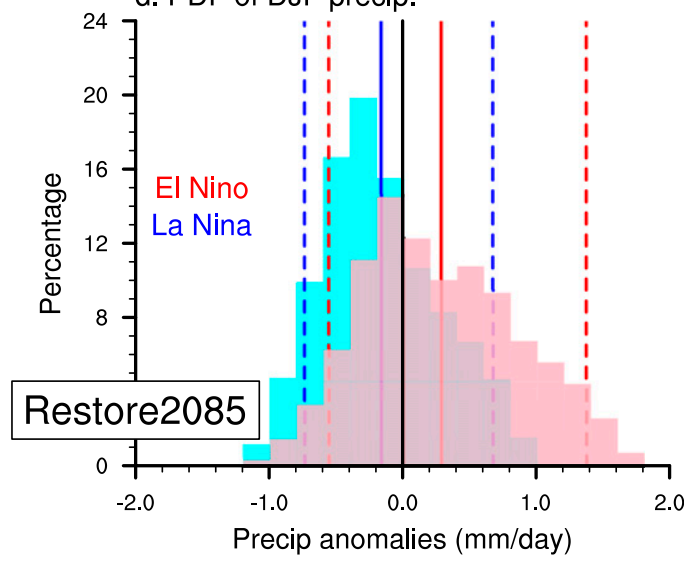

FIG. 10. As in Fig. 9, but for precipitation over the North Atlantic-Europe region.

occurs during El Niño, while changes are minor and not significant for La Niña. In a warmer climate (Fig. 10d), the reinforced teleconnectivity in atmospheric circulation leads to considerable increase probability for wet (dry) conditions during El Niño (La Niña), but more importantly, to a considerable augmentation of the risk for more extreme rainfall winters, which is materialized by a pronounced increase in the variance of the distribution during El Niño. The 95th percentile is equal to $0.7 \mathrm{~mm} \mathrm{day}^{-1}$ in restorePIC but reaches $1.35 \mathrm{~mm} \mathrm{day}^{-1}$ in restore2085.

This finding provides additional evidence that mean background states play indeed a role in teleconnectivity when assessed from atmospheric dynamics but also that the latter response could be amplified by thermodynamical processes as shown here for precipitation off southern Europe (Fig. 10) and for surface temperature over North America (Fig. 9). Coupling with ocean + sea ice (allowed in the present study through pacemaker framework) as opposed to AMIP configuration, is expected to act as a positive feedback of great importance to amplify the sensitivity due to the sole background-forced atmospheric shifted circulation during ENSO [see, e.g., Drévillon et al. (2003) for the extratropical Atlantic].

\section{Summary and discussion}

In the present paper, we specifically focus on the modification of the ENSO-driven wintertime teleconnection in the North Pacific and NAE domains in a warmer background climate state.

To narrow and simplify this broad issue, we adopt the "null hypothesis" of "no future change in ENSO SST statistics" and accordingly design a dedicated modeling protocol based on pacemaker ensemble experiments using the CNRM-CM5 coupled GCM. Several intercomparison papers (e.g., Flato et al. 2013; Bellenger et al. 2014) have highlighted the good skill and reliability of the latter model in simulating ENSO basic processes. 
Simulations are conducted with equilibrium radiative forcing to avoid potential spurious interpretations of the changes due to transient behavior found in classical available twenty-first-century projections in CMIP exercises. The null hypothesis for ENSO-related SST change in a warmer world is not a strong and limiting assumption for CNRM-CM5 that has been categorized among conservative/stable models in most of the CMIP5 multimodel studies on ENSO (e.g., Stevenson 2012; Bonfils et al. 2015; Zheng et al. 2018). We have, here, produced two pacemaker multimember simulations. These share, by construction, the same ENSO temporality over 30 years but only differ by their mean climate state. Contrasting the two 10-member ensembles makes it possible to isolate the impact of the mean background climate change between the preindustrial period and the end of the twenty-first century. This ensemble size is large enough to statistically detect changes in the ENSO teleconnection (like the eastward shift of the Aleutian low) in a warmer climate; in CNRM-CM5, four 30-yr members are sufficient (not shown).

First, our findings in the Pacific confirm earlier results:

- In the tropics, we also observe the eastward shift in the precipitation response to ENSO in a warmer climate (Fig. 4) seen in previous studies (Meehl and Teng 2007; Stevenson 2012; Power et al. 2013; Cai et al. 2014; Zhou et al. 2014; Huang and Xie 2015; Cai et al. 2017, among others).

- In the extratropics, the wintertime ENSO-induced teleconnections over the North Pacific-American domain are displaced eastward and a significant anticyclonic ridge emerges to the west of the date line (Fig. 3).

The overall extratropical response in a warmer climate during ENSO is consistent with the combined effect of (i) intensified reduction of diabatic heating over the western tropical Pacific and Maritime Continent and (ii) eastward-displaced and reinforced diabatic sources in the eastern tropical Pacific, leading to forced Rossby wave excitation [see, e.g., Zheng et al. (2013) and Trenberth et al. (1998) for the two sides of the basin]. Note that the eastward shift of the ENSO-driven teleconnection over the North Pacific appears to be slightly more pronounced compared to other studies, even to those using CNRM-CM5 projections from the CMIP5 archive (e.g., Zhou et al. 2014; Huang 2016) where a similar approach to ours is followed but in AMIP-type of experiments. Amplification/a clearer signal can be here related to several reasons: (i) we use equilibrium background states instead of transient warming; (ii) the full coupling (outside of the eastern tropical Pacific) ensures the adjustment of extratropical SST anomalies to the shifted midlatitude atmospheric circulation in response to ENSO migrated tropical source, thus allowing for amplification through local air-sea interaction (e.g., Alexander et al. 2006; Kwon et al. 2011) (as opposed to AMIP configuration); (iii) our pacemaker experiments are conducted in a perfect model framework, which could therefore generate a stronger response; and/or (iv) two ensembles of 10 members of 30 years each are used to account at best for internal climate variability arising from ENSO events diversity (see the methods section).

Second, our major findings concern the changes in the winter ENSO teleconnection over the North Atlantic domain:

- First, the forced signal in a warmer climate projects on the NAO in agreement with Müller and Roeckner (2008) and Herceg Bulić et al. (2012) (Fig. 3). This is a strong change as no signal is observed over the NAE domain in response to ENSO in the preindustrial climate.

- Second, this change seems to be mostly explained by a greater sensitivity of the North Atlantic atmosphere to La Niña events (Figs. 5-8). Indeed, NAO+ (NAO-) circulations are clearly more recurrent (inhibited) in the latter case as assessed through weather regime clustering (Fig. 5) and composite techniques applied to several dynamical atmospheric fields (Figs. 6-8).

In the preindustrial climate, the North Atlantic-ENSO teleconnectivity exists mostly during El Niño (Fig. 7) but remains confined westward along the southern flank of the storm track. No significant ENSO influence is found at basin scale because of dominant noise (large spread between ensemble members due to internal climate variability, Fig. 2), which complicates the detection of any climate change fingerprint in ENSO-driven observed teleconnection over the historical period. This appears to be fairly robust across models (e.g., Deser et al. 2017). We have verified that the simulated diversity of the ENSO-NAO teleconnection produced by the model is within the range of observational uncertainties due to sampling (not shown) and we are therefore confident that our results are not affected by critical model biases in the ENSO-NAO link.

Third, we presented two possible mechanisms to explain the reinforced and extended ENSO teleconnection up to Europe in a warmer climate:

- The first one relies on the eastward displacement of the ENSO-forced large-scale Rossby wave train over the North American continent, which extends to the North Atlantic. This favors the connection between the Icelandic low and the PNA-related center over Canada (see ensemble means in Fig. 3 
vs Fig. 2). Transient eddy-mean flow interaction is expected to play a significant role to intensify and broaden the teleconnection over the entire basin as evidenced by the emergence of a clear signal of opposite sign over the Azores.

- The second concurrent mechanism is related to the change in the Northern Hemisphere mean jet in the future climate (independently of ENSO): the North Pacific and North Atlantic jets are better connected in the warmer climate because of the combination of a stronger and more eastward-extended North Pacific jet and a southward-shifted North Atlantic jet (Fig. 8a). This clearly reinforces the waveguide property of the jet and allows more synoptic eddies originating in the North Pacific to travel toward the North Atlantic across the North American continent (Branstator 2002). Consequently, synoptic Rossby waves travel faster at the tail end of the Pacific storm track, then enter into the North Atlantic with more energy and penetrate farther east and southward in a warmer climate. Such a connection was rare during La Niña in the preindustrial climate due to the westward retraction of the Pacific jet leading to a clear separation between the Pacific and Atlantic mean jets/storm tracks. It is, however, active in a warmer climate because of the importance of the changes in the background state and despite the fact that the large-scale La Niña-forced response still exists in the North Pacific (Fig. 8b). The low-frequency La Niña-induced ridge over the North Pacific (Fig. 6) favors southwestnortheast tilt of the more energetic Pacific-generated synoptic eddies that are more likely to break anticyclonically on the southern flank of the mean Atlantic jet leading to NAO + through eddy-mean flow interaction. During El Niño events, Pacific-Atlantic connection is present, albeit weak, in the preindustrial climate but appears reinforced in a warmer state leading to larger impacts up to Europe.

A third concurrent mechanism via the western tropical Atlantic could also explain the stronger ENSO teleconnection over the North Atlantic. ENSO-forced changes in Walker cell are associated with altered local Hadley cell leading to enhanced subsidence over northern part of South America compensated by reinforced ascendance over the Caribbean during El Niño (not shown). Some asymmetry occurs during La Niña because of possible interaction with the overall mean changes characterized by a stronger climatological subsidence over the entire tropical Atlantic in a warmer climate [see, e.g., Ma et al. (2018) for a review]. The direct impact from the altered tropical dynamics in the western Atlantic known as a source of teleconnection for the NAO through Rossby wave excitation (e.g., Cassou and Terray 2001) would, however, require further investigation.

To finish, it would be interesting to repeat the above diagnostics/experimental setup with other models in order to evaluate the robustness of the changes obtained from CNRM-CM5. Our findings may be model dependent and functions of (i) the intrinsic mean biases in the model atmospheric extratropical circulation (e.g., position/strength of the mean jets), (ii) the model climate sensitivity to greenhouse gas forcing (e.g., spatial properties and amplitude of the altered mean background state), and (iii) the model resolution both horizontally (e.g., strength and realism of the synoptic eddies and associated mean flow interaction) and vertically [e.g., importance and evolution of stratospheric processes in relation with ENSO as suggested from Ineson and Scaife (2009) and Li and Lau (2013), among others]. In any case, beyond future climate changes, our findings have some strong implications for past climate reconstruction from remote proxies because most of the studies are calibrated on recent historical period and assume stationarity in ENSO teleconnections (e.g., McGregor et al. 2010; Li et al. 2013). We here demonstrate that this working hypothesis might be too assertive and might be a source of significant uncertainties for past variability assessment over land, on top of very pronounced internal variability as also emphasized by our modeling protocol using ensembles.

Acknowledgments. The authors thank three anonymous reviewers for their constructive comments and suggestions. This research was carried out within the MORDICUS project funded by the French Agence Nationale de la Recherche (ANR-13-SENV-0002-02). M.D. was also funded by the NERC project Robust Spatial Projections of Real-World Climate Change (NE/ N01815X/1). This study has benefited from discussions with Thomas Oudar, Philippe Arbogast, and Javier García-Serrano. The authors are grateful to MariePierre Moine, Laure Coquart, and Isabelle Dast for technical help to run the model. Computer resources have been provided by CERFACS. The authors wish to acknowledge the use of the NCAR Command Language Software (http://dx.doi.org/10.5065/D6WD3XH5) and the Ferret program (http://ferret.pmel.noaa.gov/ Ferret/) for analysis and graphics.

\section{REFERENCES}

Alexander, L., and Coauthors, 2006: Global observed changes in daily climate extremes of temperature and precipitation. J. Geophys. Res., 111, D05109, https://doi.org/10.1029/ 2005JD006290. 
Ayarzagüena, B., J. López-Parages, M. Iza, N. Calvo, and B. Rodríguez-Fonseca, 2019: Stratospheric role in interdecadal changes of El Niño impacts over Europe. Climate Dyn., 52, 1173-1186, https://doi.org/10.1007/S00382-018-4186-3.

Bellenger, H., É. Guilyardi, J. Leloup, M. Lengaigne, and J. Vialard, 2014: ENSO representation in climate models: From CMIP3 to CMIP5. Climate Dyn., 42, 1999-2018, https:// doi.org/10.1007/s00382-013-1783-z.

Benedict, J. J., S. Lee, and S. B. Feldstein, 2004: Synoptic view of the North Atlantic Oscillation. J. Atmos. Sci., 61, 121-144, https:// doi.org/10.1175/1520-0469(2004)061<0121:SVOTNA >2.0.CO;2.

Boer, G. J., and Coauthors, 2016: The Decadal Climate Prediction Project (DCPP) contribution to CMIP6. Geosci. Model Dev., 9, 3751-3777, https://doi.org/10.5194/gmd-93751-2016.

Bonfils, C. J., B. D. Santer, T. J. Phillips, K. Marvel, L. R. Leung, C. Doutriaux, and A. Capotondi, 2015: Relative contributions of mean-state shifts and ENSO-driven variability to precipitation changes in a warming climate. J. Climate, 28, 999710013 , https://doi.org/10.1175/JCLI-D-15-0341.1.

Brands, S., 2017: Which ENSO teleconnections are robust to internal atmospheric variability? Geophys. Res. Lett., 44, 14831493, https://doi.org/10.1002/2016GL071529.

Branstator, G., 2002: Circumglobal teleconnections, the jet stream waveguide, and the North Atlantic Oscillation. J. Climate, 15, 1893-1910, https://doi.org/10.1175/1520-0442(2002)015<1893: CTTJSW $>2.0 . \mathrm{CO} ; 2$.

Brönnimann, S., 2007: Impact of El Niño-Southern Oscillation on European climate. Rev. Geophys., 45, RG3003, https://doi.org/ 10.1029/2006RG000199.

Cai, W., and Coauthors, 2014: Increasing frequency of extreme El Niño events due to greenhouse warming. Nat. Climate Change, 4, 111-116, https://doi.org/10.1038/nclimate2100.

— , and Coauthors, 2015: ENSO and greenhouse warming. Nat. Climate Change, 5, 849, https://doi.org/10.1038/nclimate2743.

—_ G. Wang, A. Santoso, X. Lin, and L. Wu, 2017: Definition of extreme El Niño and its impact on projected increase in extreme El Niño frequency. Geophys. Res. Lett., 44, 11184 11 190, https://doi.org/10.1002/2017GL075635.

Capotondi, A., and Coauthors, 2015: Understanding ENSO diversity. Bull. Amer. Meteor. Soc., 96, 921-938, https://doi.org/ 10.1175/BAMS-D-13-00117.1.

Cassou, C., 2008: Intraseasonal interaction between the MaddenJulian Oscillation and the North Atlantic Oscillation. Nature, 455, 523-527, https://doi.org/10.1038/nature07286.

, and L. Terray, 2001: Oceanic forcing of the wintertime low-frequency atmospheric variability in the North Atlantic European sector: A study with the ARPEGE model. J. Climate, 14, 4266-4291, https://doi.org/10.1175/15200442(2001)014<4266:OFOTWL>2.0.CO;2.

Chen, T.-C., 2002: A North Pacific short-wave train during the extreme phases of ENSO. J. Climate, 15, 2359-2376, https://doi.org/ 10.1175/1520-0442(2002)015<2359:ANPSWT>2.0.CO;2.

Christensen, J. H., and Coauthors, 2013: Climate phenomena and their relevance for future regional climate change. Climate Change 2013: The Physical Science Basis, T. F. Stocker et al., Eds., Cambridge University Press, 1217-1308.

Collins, M., 2000: Understanding uncertainties in the response of ENSO to greenhouse warming. Geophys. Res. Lett., 27, 35093512, https://doi.org/10.1029/2000GL011747.

_- and Coauthors, 2005: El Niño- or La Niña-like climate change? Climate Dyn., 24, 89-104, https://doi.org/10.1007/ s00382-004-0478-x.
Déqué, M., C. Dreveton, A. Braun, and D. Cariolle, 1994: The ARPEGE/IFS atmosphere model: A contribution to the French community climate modelling. Climate Dyn., 10, 249266, https://doi.org/10.1007/BF00208992.

Deser, C., I. R. Simpson, K. A. McKinnon, and A. S. Phillips, 2017: The Northern Hemisphere extratropical atmospheric circulation response to ENSO: How well do we know it and how do we evaluate models accordingly? J. Climate, 30, 5059-5082, https://doi.org/10.1175/JCLI-D-16-0844.1.

,,-- A. S. Phillips, and K. A. McKinnon, 2018: How well do we know ENSO's climate impacts over North America, and how do we evaluate models accordingly? J. Climate, 31, 49915014, https://doi.org/10.1175/JCLI-D-17-0783.1.

Domeisen, D. I., A. H. Butler, K. Fröhlich, M. Bittner, W. A. Müller, and J. Baehr, 2015: Seasonal predictability over Europe arising from El Niño and stratospheric variability in the MPI-ESM seasonal prediction system. J. Climate, 28, 256-271, https://doi.org/10.1175/JCLI-D-14-00207.1.

Dong, B.-W., R. Sutton, S. Jewson, A. O'Neill, and J. Slingo, 2000: Predictable winter climate in the North Atlantic sector during the 1997-1999 ENSO cycle. Geophys. Res. Lett., 27, 985-988, https://doi.org/10.1029/1999GL010994.

Drévillon, M., C. Cassou, and L. Terray, 2003: Model study of the North Atlantic region atmospheric response to autumn tropical Atlantic sea-surface-temperature anomalies. Quart. J. Roy. Meteor. Soc., 129, 2591-2611, https://doi.org/10.1256/ qj.02.17.

Drouard, M., G. Rivière, and P. Arbogast, 2015: The link between the North Pacific climate variability and the North Atlantic Oscillation via downstream propagation of synoptic waves. J. Climate, 28, 3957-3976, https://doi.org/ 10.1175/JCLI-D-14-00552.1.

Duchon, C. E., 1979: Lanczos filtering in one and two dimensions. J. Appl. Meteor., 18, 1016-1022, https://doi.org/10.1175/15200450(1979)018<1016:LFIOAT > 2.0.CO;2.

Fischer, E. M., D. M. Lawrence, and B. M. Sanderson, 2011: Quantifying uncertainties in projections of extremes-A perturbed land surface parameter experiment. Climate Dyn., 37, 1381-1398, https://doi.org/10.1007/s00382-010-0915-y.

Flato, G., and Coauthors, 2013: Evaluation of climate models. Climate Change 2013: The Physical Science Basis, T. F. Stocker et al., Eds., Cambridge University Press, 741-866.

Fraedrich, K., 1990: European grosswetter during the warm and cold extremes of the $\mathrm{El} \mathrm{Niño/Southern} \mathrm{Oscillation.} \mathrm{Int}$ J. Climatol., 10, 21-31, https://doi.org/10.1002/joc.3370100104. - and K. Müller, 1992: Climate anomalies in Europe associated with ENSO extremes. Int. J. Climatol., 12, 25-31, https:// doi.org/10.1002/joc.3370120104.

Franzke, C., S. Lee, and S. B. Feldstein, 2004: Is the North Atlantic Oscillation a breaking wave? J. Atmos. Sci., 61, 145-160, https://doi.org/10.1175/1520-0469(2004)061<0145: ITNAOA $>2.0 . \mathrm{CO} ; 2$.

Haney, R. L., 1971: Surface thermal boundary condition for ocean circulation models. J. Oceanogr., 1, 241-248, https://doi.org/ 10.1175/1520-0485(1971)001<0241:STBCFO > 2.0.CO;2.

Hawkins, E., R. S. Smith, J. M. Gregory, and D. A. Stainforth, 2016: Irreducible uncertainty in near-term climate projections. Climate Dyn., 46, 3807-3819, https://doi.org/10.1007/s00382-015-2806-8.

Herceg Bulić, I. H., Ć. Branković, and F. Kucharski, 2012: Winter ENSO teleconnections in a warmer climate. Climate Dyn., 38, 1593-1613, https://doi.org/10.1007/s00382-010-0987-8.

Horel, J. D., and J. M. Wallace, 1981: Planetary-scale atmospheric phenomena associated with the Southern Oscillation. Mon. 
Wea. Rev., 109, 813-829, https://doi.org/10.1175/1520-0493(1981) $109<0813:$ PSAPAW $>2.0 . \mathrm{CO} ; 2$.

Hoskins, B. J., and D. J. Karoly, 1981: The steady linear response of a spherical atmosphere to thermal and orographic forcing. J. Atmos. Sci., 38, https://doi.org/10.1175/1520-0469(1981) $038<1179$ :TSLROA $>2.0$. CO 2 .

Huang, P., 2016: Time-varying response of ENSO-induced tropical Pacific rainfall to global warming in CMIP5 models. Part I: Multimodel ensemble results. J. Climate, 29, 5763-5778, https://doi.org/10.1175/JCLI-D-16-0058.1.

_ , and S.-P. Xie, 2015: Mechanisms of change in ENSO-induced tropical Pacific rainfall variability in a warming climate. Nat. Geosci., 8, 922-926, https://doi.org/10.1038/ngeo2571.

Ineson, S., and A. Scaife, 2009: The role of the stratosphere in the European climate response to El Niño. Nat. Geosci., 2, 32-36, https://doi.org/10.1038/ngeo381.

Jiménez-Esteve, B., and D. I. Domeisen, 2018: The tropospheric pathway of the ENSO-North Atlantic teleconnection. J. Climate, 31, 4563-4584, https://doi.org/10.1175/ JCLI-D-17-0716.1.

Kosaka, Y., and S.-P. Xie, 2013: Recent global-warming hiatus tied to equatorial Pacific surface cooling. Nature, 501, 403-407, https://doi.org/10.1038/nature12534.

Kug, J.-S., S.-I. An, Y.-G. Ham, and I.-S. Kang, 2010: Changes in El Niño and La Niña teleconnections over North Pacific-America in the global warming simulations. Theor. Appl. Climatol., 100, 275-282, https://doi.org/10.1007/s00704-009-0183-0.

Kwon, Y.-O., C. Deser, and C. Cassou, 2011: Coupled atmospheremixed layer ocean response to ocean heat flux convergence along the Kuroshio Current Extension. Climate Dyn., 36, 2295-2312, https://doi.org/10.1007/s00382-010-0764-8.

Lau, N.-C., and M. J. Nath, 1994: A modeling study of the relative roles of tropical and extratropical SST anomalies in the variability of the global atmosphere-ocean system. J. Climate, $\mathbf{7}$, 1184-1207, https://doi.org/10.1175/1520-0442(1994)007<1184: AMSOTR $>2.0 . \mathrm{CO} ; 2$

Li, J., and Coauthors, 2013: El Niño modulations over the past seven centuries. Nat. Climate Change, 3, 822-826, https:// doi.org/10.1038/nclimate1936.

Li, Y., and N.-C. Lau, 2012a: Impact of ENSO on the atmospheric variability over the North Atlantic in late winter-Role of transient eddies. J. Climate, 25, 320-342, https://doi.org/ 10.1175/JCLI-D-11-00037.1.

$\longrightarrow$, and $\longrightarrow, 2012 \mathrm{~b}$ : Contributions of downstream eddy development to the teleconnection between ENSO and the atmospheric circulation over the North Atlantic. J. Climate, 25, 4993-5010, https://doi.org/10.1175/JCLI-D-11-00377.1.

- and - 2013: Influences of ENSO on stratospheric variability, and the descent of stratospheric perturbations into the lower troposphere. J. Climate, 26, 4725-4748, https://doi.org/ 10.1175/JCLI-D-12-00581.1.

Lin, H., J. Derome, and G. Brunet, 2005: Tropical Pacific link to the two dominant patterns of atmospheric variability. Geophys. Res. Lett., 32, L03801, https://doi.org/10.1029/2004GL021495.

López-Parages, J., B. Rodríguez-Fonseca, and L. Terray, 2015: A mechanism for the multidecadal modulation of ENSO teleconnection with Europe. Climate Dyn., 45, 867-880, https:// doi.org/10.1007/s00382-014-2319-x.

Ma, J., R. Chadwick, K.-H. Seo, C. Dong, G. Huang, G. R. Foltz, and J. H. Jiang, 2018: Responses of the tropical atmospheric circulation to climate change and connection to the hydrological cycle. Annu. Rev. Earth Planet. Sci., 46, 549-580, https://doi.org/10.1146/annurev-earth-082517-010102.
Madec, G., 2008: NEMO ocean engine. Note du Pôle modélisation. Institut Pierre-Simon Laplace, 209 pp.

Manola, I., F. Selten, H. Vries, and W. Hazeleger, 2013: "Waveguidability" of idealized jets. J. Geophys. Res. Atmos., 118, 10 432-10 440, https://doi.org/10.1002/JGRD.50758.

Marshall, J., and F. Molteni, 1993: Toward a dynamical understanding of planetary-scale flow regimes. J. Atmos. Sci., 50, 1792-1818, https://doi.org/10.1175/1520-0469(1993)050<1792: TADUOP $>2.0 . C O ; 2$.

McGregor, S., A. Timmermann, and O. Timm, 2010: A unified proxy for ENSO and PDO variability since 1650. Climate Past, 6, 1-17, https://doi.org/10.5194/cp-6-1-2010.

Meehl, G. A., and H. Teng, 2007: Multi-model changes in El Niño teleconnections over North America in a future warmer climate. Climate Dyn., 29, 779-790, https://doi.org/10.1007/ s00382-007-0268-3.

,,-- and G. Branstator, 2006: Future changes of El Niño in two global coupled climate models. Climate Dyn., 26, 549-566, https://doi.org/10.1007/s00382-005-0098-0.

Michelangeli, P.-A., R. Vautard, and B. Legras, 1995: Weather regimes: Recurrence and quasi stationarity. J. Atmos. Sci., 52, 1237-1256, https://doi.org/10.1175/1520-0469(1995)052<1237: WRRAQS $>2.0 . \mathrm{CO} ; 2$.

Molteni, F., F. Kuscharski, and S. Corti, 2006: On the predictability of flow regime properties on interannual to interdecadal timescales. Predictability of Weather and Climate, T. Palmer and R. Hagedorn, Eds., Cambridge University Press, 365-389.

Moron, V., and I. Gouirand, 2003: Seasonal modulation of the El Niño-Southern Oscillation relationship with sea level pressure anomalies over the North Atlantic in October-March 1873-1996. Int. J. Climatol., 23, 143-155, https://doi.org/ 10.1002/joc.868.

Müller, W., and E. Roeckner, 2008: Enso teleconnections in projections of future climate in ECHAM5/MPI-OM. Climate Dyn., 31, 533-549, https://doi.org/10.1007/s00382007-0357-3.

Oudar, T., E. Sanchez-Gomez, F. Chauvin, J. Cattiaux, L. Terray, and C. Cassou, 2017: Respective roles of direct GHG radiative forcing and induced Arctic sea ice loss on the Northern Hemisphere atmospheric circulation. Climate Dyn., 49, 36933713, https://doi.org/10.1007/s00382-017-3541-0.

Power, S., F. Delage, C. Chung, G. Kociuba, and K. Keay, 2013: Robust twenty-first-century projections of El Niño and related precipitation variability. Nature, 502, 541-545, https://doi.org/ 10.1038/nature12580.

Pozo-Vázquez, D., M. Esteban-Parra, F. Rodrigo, and Y. CastroDiez, 2001: The association between ENSO and winter atmospheric circulation and temperature in the North Atlantic region. J. Climate, 14, 3408-3420, https://doi.org/10.1175/15200442(2001)014<3408:TABEAW >2.0.CO;2.

, S. Gámiz-Fortis, J. Tovar-Pescador, M. Esteban-Parra, and Y. Castro-Díez, 2005: El Niño-Southern Oscillation events and associated European winter precipitation anomalies. Int. J. Climatol., 25, 17-31, https://doi.org/10.1002/joc.1097.

Reinhold, B. B., and R. T. Pierrehumbert, 1982: Dynamics of weather regimes: Quasi-stationary waves and blocking. Mon. Wea. Rev., 110, 1105-1145, https://doi.org/10.1175/ 1520-0493(1982) $110<1105$ :DOWRQS $>2.0$. CO;2.

Rivière, G., and I. Orlanski, 2007: Characteristics of the Atlantic storm-track eddy activity and its relation with the North Atlantic Oscillation. J. Atmos. Sci., 64, 241-266, https://doi.org/ 10.1175/JAS3850.1. 
— B. Hua, and P. Klein, 2003: Perturbation growth in terms of barotropic alignment properties. Quart. J. Roy. Meteor. Soc., 129, 2613-2635, https://doi.org/10.1256/qj.02.106.

Salas Mélia, D., 2002: A global coupled sea ice-ocean model. Ocean Modell., 4, 137-172, https://doi.org/10.1016/ S1463-5003(01)00015-4.

Sanchez-Gomez, E., C. Cassou, Y. Ruprich-Robert, E. Fernandez, and L. Terray, 2016: Drift dynamics in a coupled model initialized for decadal forecasts. Climate Dyn., 46, 1819-1840, https://doi.org/10.1007/s00382-015-2678-y.

Stevenson, S. L., 2012: Significant changes to ENSO strength and impacts in the twenty-first century: Results from CMIP5. Geophys. Res. Lett., 39, https://doi.org/10.1029/ 2012 GL052759.

Straus, D. M., and J. Shukla, 2002: Does ENSO force the PNA? J. Climate, 15, 2340-2358, https://doi.org/10.1175/ 1520-0442(2002)015<2340:DEFTP > 2.0.CO;2.

— S. Corti, and F. Molteni, 2007: Circulation regimes: Chaotic variability versus SST-forced predictability. J. Climate, 20, 2251-2272, https://doi.org/10.1175/JCLI4070.1.

Strong, C., and G. Magnusdottir, 2008: Tropospheric Rossby wave breaking and the NAO/NAM. J. Atmos. Sci., 65, 2861-2876, https://doi.org/10.1175/2008JAS2632.1.

Taylor, K. E., R. J. Stouffer, and G. A. Meehl, 2012: An overview of CMIP5 and the experiment design. Bull. Amer. Meteor. Soc., 93, 485-498, https://doi.org/10.1175/BAMS-D-11-00094.1.

Trenberth, K., 1986: An assessment of the impact of transient eddies on the zonal flow during a blocking episode using localized Eliassen-Palm flux diagnostics. J. Atmos. Sci., 43, 2070-2087, https://doi.org/10.1175/1520-0469(1986)043<2070: AAOTIO $>2.0 . \mathrm{CO} ; 2$.

, G. W. Branstator, D. Karoly, A. Kumar, N.-C. Lau, and C. Ropelewski, 1998: Progress during TOGA in understanding and modeling global teleconnections associated with tropical sea surface temperatures. J. Geophys. Res., 103, 14 291-14324, https://doi.org/10.1029/97JC01444.

Valcke, S., 2013: The OASIS3 coupler: A European climate modelling community software. Geosci. Model Dev., 6, 373388, https://doi.org/10.5194/gmd-6-373-2013.

Vallis, G. K., and E. P. Gerber, 2008: Local and hemispheric dynamics of the North Atlantic Oscillation, annular patterns and the zonal index. Dyn. Atmos. Oceans, 44, 184-212, https:// doi.org/10.1016/j.dynatmoce.2007.04.003.

Van Loon, H., and R. A. Madden, 1981: The Southern Oscillation. Part I: Global associations with pressure and temperature in northern winter. Mon. Wea. Rev., 109, 1150-1162, https://doi.org/10.1175/1520-0493(1981) $109<1150$ :TSOPIG $>2.0 . \mathrm{CO} ; 2$.

Vautard, R., 1990: Multiple weather regimes over the North Atlantic: Analysis of precursors and successors. Mon. Wea. Rev., 118, 2056-2081, https://doi.org/10.1175/1520-0493(1990) $118<2056$ :MWROTN $>2.0 . \mathrm{CO} ; 2$.

Voldoire, A., and Coauthors, 2013: The CNRM-CM5.1 global climate model: Description and basic evaluation. Climate Dyn., 40, 2091-2121, https://doi.org/10.1007/s00382-011-1259-y.

Wallace, J. M., and D. S. Gutzler, 1981: Teleconnections in the geopotential height field during the Northern Hemisphere winter. Mon. Wea. Rev., 109, 784-812, https://doi.org/10.1175/ 1520-0493(1981)109<0784:TITGHF > 2.0.CO;2.

Woollings, T., B. Hoskins, M. Blackburn, and P. Berrisford, 2008: A new Rossby wave-breaking interpretation of the North Atlantic Oscillation. J. Atmos. Sci., 65, 609-626, https:// doi.org/10.1175/2007JAS2347.1.

Xie, S.-P., C. Deser, G. A. Vecchi, J. Ma, H. Teng, and A. T. Wittenberg, 2010: Global warming pattern formation: Sea surface temperature and rainfall. J. Climate, 23, 966-986, https://doi.org/10.1175/2009JCLI3329.1.

Yeh, S.-W., and Coauthors, 2018: ENSO atmospheric teleconnections and their response to greenhouse gas forcing. Rev. Geophys., 56, 185-206, https://doi.org/10.1002/2017RG000568.

Zheng, J., Q. Liu, C. Wang, and X.-T. Zheng, 2013: Impact of heating anomalies associated with rainfall variations over the Indo-western Pacific on Asian atmospheric circulation in winter. Climate Dyn., 40, 2023-2033, https://doi.org/10.1007/s00382-012-1478-x.

Zheng, X.-T., C. Hui, and S.-W. Yeh, 2018: Response of ENSO amplitude to global warming in CESM large ensemble: Uncertainty due to internal variability. Climate Dyn., 50, 40194035, https://doi.org/10.1007/s00382-017-3859-7.

Zhou, Z.-Q., S.-P. Xie, X.-T. Zheng, Q. Liu, and H. Wang, 2014: Global warming-induced changes in El Niño teleconnections over the North Pacific and North America. J. Climate, 27, 9050-9064, https://doi.org/10.1175/JCLI-D-14-00254.1. 